Elsevier required licence: ( 2019

This manuscript version is made available under the CC-BY-NC-ND 4.0 license http://creativecommons.org/licenses/by-nc-nd/4.0/

The definitive publisher version is available online at https://doi..org/10.1016/j.ijepes.2019.04.040 


\title{
Optimal operation of an energy hub considering the uncertainty associated with the power consumption of plug-in hybrid electric vehicles using information gap decision theory
}

\author{
Seyed Masoud Moghaddas-Tafreshia, ${ }^{a,}$, Morteza Jafari ${ }^{a}$, Soheil Mohseni ${ }^{a, b}$, Scott Kelly ${ }^{c}$ \\ ${ }^{a}$ Department of Electrical Engineering, Faculty of Engineering, University of Guilan, Rasht, Iran \\ ${ }^{b}$ Chair in Sustainable Energy Systems, School of Engineering and Computer Science, Faculty of Engineering, Victoria \\ University of Wellington, Wellington 6140, New Zealand \\ ${ }^{c}$ Institute for Sustainable Futures, University of Technology Sydney, NSW, Australia \\ * Corresponding author, Email: tafreshi@guilan.ac.ir
}

\begin{abstract}
An energy hub is a multi-carrier energy system that is capable of coupling various energy networks. It increases the flexibility of energy management and creates opportunities to increase the efficiency and reliability of energy systems. When plug-in hybrid electric vehicles (PHEVs) are incorporated into the energy hub, batteries can act as an aggregated storage system, increasing the potential integration of variable renewable energy sources (RES) into power system networks. This paper presents a new model for the optimal operation of an energy hub that includes RES, PHEVs, fuel cell vehicles, a fuel cell, an electrolyzer, a hydrogen tank, a boiler, an inverter, a rectifier, and a heat storage system. A novel model is developed to estimate the uncertainty associated with the power consumption of PHEVs during trips using information gap decision theory (IGDT) under risk-averse and risk-seeking strategies. Simulation results demonstrate that the proposed method maximizes the objective function under the risk-neutral and risk-averse strategies, while minimizing the objective function under the risk-seeking strategy. Results from the modeling show that considering the uncertainty associated with the power consumption of PHEVs using IGDT enables the energy hub operator to make appropriate decisions when optimizing the operation of the energy hub against possible changes in power consumption of PHEVs.
\end{abstract}

Keywords: Energy hub; Optimal operation; Information gap decision theory (IGDT); Plug-in hybrid electric vehicle (PHEV); Fuel cell vehicle (FCV).

\begin{tabular}{|c|c|c|c|}
\hline \multicolumn{4}{|l|}{ Nomenclature } \\
\hline Acronyms & & $P_{r}$ & rated power of wind turbines $[\mathrm{kW}]$ \\
\hline CHP & combined heat and power & Variables & \\
\hline EL & electrical loads & $\alpha$ & a number between 0 and 1 \\
\hline $\mathrm{EP}$ & electricity price & $V_{V}$ & $\begin{array}{l}\text { average driving speed of the } V^{\text {th }} \\
\text { PHEV }[\mathrm{km} / \mathrm{h}]\end{array}$ \\
\hline FCVs & fuel cell vehicles & $\delta_{1}, \delta_{2}$ & $\begin{array}{l}\text { deviation factors under the risk- } \\
\text { averse and risk-seeking strategies }\end{array}$ \\
\hline GAMS & general algebraic modeling system & $P r_{d}, P r_{c}, P r_{w}$ & $\begin{array}{l}\text { deterministic, critical, and target } \\
\text { profits }[\$]\end{array}$ \\
\hline GAs & genetic algorithms & $V$ & wind speed $[\mathrm{m} / \mathrm{s}]$ \\
\hline GP & gas price & $G_{t}$ & $\begin{array}{l}\text { total solar radiation incident on the } \\
\text { tilted panel }\left[\mathrm{W} / \mathrm{m}^{2}\right]\end{array}$ \\
\hline HL & hydrogen loads & $\pi^{e}$ & electricity price $[\$ / \mathrm{kWh}]$ \\
\hline IGDT & information gap decision theory & $\pi^{g}$ & natural gas price $[\$ / \mathrm{kWh}]$ \\
\hline MSOS & $\begin{array}{l}\text { modified symbiotic organisms } \\
\text { search }\end{array}$ & $P_{V}^{c o n s}$ & $\begin{array}{l}\text { power consumption of the } \mathrm{V}^{\text {th }} \\
\text { PHEV }[\mathrm{kW}]\end{array}$ \\
\hline PHEVs & plug-in hybrid electric vehicles & $P_{\text {gride }}^{S}, P_{\text {gride }}^{B}$ & $\begin{array}{l}\text { sold/bought power to/from electrical } \\
\text { power grid }[\mathrm{kW}]\end{array}$ \\
\hline PSO & particle swarm optimization & $P_{\text {gridg }}$ & $\begin{array}{l}\text { purchased power from natural gas } \\
\text { network }[\mathrm{kW}]\end{array}$ \\
\hline PV & photovoltaic & $L_{e}, L_{h}, L_{H_{2}}$ & $\begin{array}{l}\text { electrical, thermal, and hydrogen } \\
\text { load powers }[\mathrm{kW}]\end{array}$ \\
\hline RES & renewable energy sources & $E_{H_{2}}, E_{h}$ & $\begin{array}{l}\text { energy stored in the hydrogen tank } \\
\text { and thermal storage system [kWh] }\end{array}$ \\
\hline
\end{tabular}




\begin{tabular}{|c|c|c|c|}
\hline SOC & state of charge & $t_{l h}, t_{a w}, t_{l w}, t_{a h}$ & $\begin{array}{l}\text { time at which a PHEV leaves home, } \\
\text { arrives at working place, leaves } \\
\text { working place, and arrives at home } \\
\text { [h] }\end{array}$ \\
\hline SR & solar radiation & $P_{P H E V}^{c h}, P_{P H E V}^{d c h}$ & $\begin{array}{l}\text { total charging/discharging power of } \\
\text { PHEVs }[\mathrm{kW}]\end{array}$ \\
\hline $\mathrm{TL}$ & thermal loads & $P_{h}^{c h}, P_{h}^{d c h}$ & $\begin{array}{l}\text { charging/discharging power of heat } \\
\text { storage system [kW] }\end{array}$ \\
\hline WS & wind speed & $P_{P V}, P_{W T}, P_{B}, P_{E X}, P_{H_{2}}$ & $\begin{array}{l}\text { output power of photovoltaic } \\
\text { generation system, wind turbines, } \\
\text { boiler, heat exchanger, and } \\
\text { electrolyzer }[\mathrm{kW}]\end{array}$ \\
\hline WT & wind turbine & $P_{E L}$ & $\begin{array}{l}\text { power delivered from DC bus to } \\
\text { electrolyzer }[\mathrm{kW}]\end{array}$ \\
\hline Parameters & & $P_{F C}$ & $\begin{array}{l}\text { power delivered from hydrogen tank } \\
\text { to fuel cell }[\mathrm{kW}]\end{array}$ \\
\hline$\eta V$ & $\begin{array}{l}\text { energy consumption of the } \mathrm{V}^{\text {th }} \\
\text { PHEV per kilometer }[\mathrm{kWh} / \mathrm{km}]\end{array}$ & $P_{R e c}^{A C}, P_{R e c}^{D C}$ & $\mathrm{AC} / \mathrm{DC}$ power of rectifier $[\mathrm{kW}]$ \\
\hline $\begin{array}{l}\eta h, \eta H_{2}, \eta P V, \eta B \\
\eta E X, \eta F C, \eta E L, \eta I n v \\
\eta \operatorname{Rec}\end{array}$ & $\begin{array}{l}\text { thermal storage system, hydrogen } \\
\text { tank, photovoltaic generation } \\
\text { system, boiler, heat exchanger, fuel } \\
\text { cell, electrolyzer, inverter, and } \\
\text { rectifier efficiencies [\%] }\end{array}$ & $P_{\operatorname{Inv}}^{A C}, P_{\operatorname{Inv}}^{D C}$ & $\mathrm{AC} / \mathrm{DC}$ power of inverter $[\mathrm{kW}]$ \\
\hline$A_{P V}$ & $\begin{array}{l}\text { area of a single photovoltaic panel } \\
{\left[\mathrm{m}^{2}\right]}\end{array}$ & $P_{F C}^{e}, P_{F C}^{h}$ & $\begin{array}{l}\text { electrical/thermal output power of } \\
\text { fuel cell }[\mathrm{kW}]\end{array}$ \\
\hline$N_{P V}, N_{W T}$ & $\begin{array}{l}\text { number of photovoltaic panels and } \\
\text { wind turbines }\end{array}$ & $P_{V}^{c h}, P_{V}^{d c h}$ & $\begin{array}{l}\text { charging/discharging power of the } \\
\mathrm{V}^{\text {th }} \text { PHEV }[\mathrm{kW}]\end{array}$ \\
\hline$V_{\text {cin }}, V_{\text {coff }}$ & cut-in and cut-off wind speeds $[\mathrm{m} / \mathrm{s}]$ & $E_{V}$ & $\begin{array}{l}\text { energy stored in the battery of the } \\
\mathrm{V}^{\text {th }} \text { PHEV }[\mathrm{kWh}]\end{array}$ \\
\hline$r_{F C}^{h}$ & $\begin{array}{l}\text { ratio of thermal to electrical output } \\
\text { power of fuel cell }\end{array}$ & $E_{h}$ & $\begin{array}{l}\text { energy stored in the heat storage } \\
\text { system }[\mathrm{kWh}]\end{array}$ \\
\hline$P_{\text {gride }}^{\max }, P_{\text {gridg }}^{\max }$ & $\begin{array}{l}\text { maximum capacity of the line/pipe } \\
\text { connected between the energy hub } \\
\text { and upstream power grid/natural gas } \\
\text { network }[\mathrm{kW}]\end{array}$ & $E_{H_{2}}$ & $\begin{array}{l}\text { energy stored in the hydrogen tank } \\
{[\mathrm{kWh}]}\end{array}$ \\
\hline$P^{c h, \underset{V}{\max }}, P^{d c h, \max }$ & $\begin{array}{l}\text { maximum charging/discharging } \\
\text { power of the battery of the } \mathrm{V}^{\text {th }} \\
\text { PHEV }[\mathrm{kW}]\end{array}$ & $P_{h}^{c h}, P_{h}^{d c h}$ & $\begin{array}{l}\text { charging/discharging power of the } \\
\text { heat storage system [kW] }\end{array}$ \\
\hline $\operatorname{Cap}_{V}$ & $\begin{array}{l}\text { rated capacity of the } V^{\text {th }} \text { PHEV } \\
{[\mathrm{kWh}]}\end{array}$ & $S O C_{V}$ & $\begin{array}{l}\text { state of charge of the } V^{\text {th }} \text { PHEV's } \\
\text { battery [\%] }\end{array}$ \\
\hline$N$ & number of PHEVs & Binary Variables & \\
\hline$E_{V}^{\max }$ & $\begin{array}{l}\text { maximum allowable capacity of the } \\
\text { battery of the } V^{\text {th }} \text { PHEV }[\mathrm{kWh}]\end{array}$ & $X_{V}$ & $\begin{array}{l}\text { binary variable; equal to } 1 \text { if } \mathrm{PHEV} \\
\text { is charging; equal to } 0 \text { if } \mathrm{PHEV} \text { is } \\
\text { not charging }\end{array}$ \\
\hline$E_{H_{2}}^{\min }, E_{H_{2}}^{\max }$ & $\begin{array}{l}\text { minimum and maximum allowable } \\
\text { capacities of the hydrogen tank } \\
{[\mathrm{kWh}]}\end{array}$ & $Y_{V}$ & $\begin{array}{l}\text { binary variable; equal to } 1 \text { if PHEV } \\
\text { is discharging; equal to } 0 \text { if } \mathrm{PHEV} \text { is } \\
\text { not discharging }\end{array}$ \\
\hline$E_{h}^{\min }, E_{h}^{\max }$ & $\begin{array}{l}\text { minimum and maximum allowable } \\
\text { capacities of the heat storage system } \\
{[\mathrm{kWh}]}\end{array}$ & $Z_{V}$ & $\begin{array}{l}\text { binary variable; equal to } 1 \text { if PHEV } \\
\text { is plugged out; equal to } 0 \text { if } \mathrm{PHEV} \\
\text { is plugged in }\end{array}$ \\
\hline$P_{E L}^{\text {rated }}, P_{F C}^{\text {rated }}$ & $\begin{array}{l}\text { maximum rated powers of the } \\
\text { electrolyzer and fuel cell }[\mathrm{kW}]\end{array}$ & Functions & \\
\hline$V_{r}$ & nominal wind speed $[\mathrm{m} / \mathrm{s}]$ & $\hat{\alpha}\left(P r_{c}\right), \hat{\beta}\left(P r_{w}\right)$ & $\begin{array}{l}\text { Robustness and opportunity } \\
\text { functions }\end{array}$ \\
\hline
\end{tabular}




\section{Introduction}

\subsection{Motivation}

Today, increased levels of carbon dioxide in the atmosphere is one of the main environmental concerns faced by the planet. Fossil fuel consumption is a major contributor to global $\mathrm{CO} 2$ emissions and is accelerating [1]-[3]. In order to tackle these problems, several countries are driving innovation in clean energy technologies. The introduction of renewable energy sources (RES) and the advent of green vehicles such as plug-in hybrid electric vehicles (PHEVs) and fuel cell vehicles (FCVs) are two major technological trends with promising prospects for reducing $\mathrm{CO} 2$ emissions compared to business as usual [4], [5]. As the penetration of RES increases, the uncertainty associated with weatherdriven sources like solar and wind energy will have increasing impact on the reliability of distributed energy networks. In addition, increasing the number of PHEVs and FCVs imposes a large additional load on energy networks and can contribute to an increase in the peak load on the system. In order to deal with the high penetration of RES and green vehicles, energy systems must be cost-effectively integrated into existing energy networks [6]-[10].

Similar to PHEVs, FCVs are considered to be a promising solution for overcoming the depletion of fossil resources whilst also reducing carbon dioxide emissions [11]-[13]. However, previous research has found that when a large number of PHEVs and FCVs are connected to existing energy systems, technical problems arise that affect the entire network [14]-[17]. Therefore, taking into account the adaption of FCVs and their impact on the operation and management of electricity networks is important for the efficient integration of FCVs, PHEVs and RES into existing energy systems.

One promising solution for the integration of high penetration RES and green vehicles is the concept of the energy hub. The energy hub concept requires that the whole energy system is investigated across multiple energy carriers, with independent and system wide assessments completed for the conversion, storage and dispatch of energy resources in order to increase the reliability and efficiency of the system [18], [19].

The uncertainty associated with different variables (e.g. energy demand, energy supply, system losses, weather, storage capacity, etc.) within the system is one of the big challenges that system operators need to deal with. Modeling the uncertainty of these systems, therefore helps system operators to understand and optimize the future operation of the system to ongoing changes [20], [21]. PHEVs are associated with several uncertain parameters (e.g. charging time, start/end time, initial state of charge of the battery) [22]. One of the most important uncertainties for assessing the impact of PHEVs on system operation, is the amount of power consumed during trips and the quantity of charge or discharge load required from/to the network when connected [23].

Information gap decision theory (IGDT) is used in this paper to handle the uncertainty associated with the amount of power consumed from PHEVs batteries during trips. The IGDT, which was first introduced by Ben-Haim [24], supports decision making in an uncertain environment. In contrast to probabilistic and possibilistic decision theories, it does not use a probability density function or a membership function. It is worth noting that the IGDT measures the deviation of errors and offers reasonable solutions when little information is available. Two strategies can be chosen by a decision maker while using the IGDT method for managing an uncertain variable: risk-averse (robust decisionmaking) and risk-seeking (opportunistic decision-making). In the risk-averse strategy, the decision maker attempts to make robust decisions against the possible errors of the uncertain variable. On the other hand, in the risk-seeking strategy, the decision variables are set to take advantage of the existing uncertainties using the lack of information [24]-[26].

The optimal operation of energy hubs is necessary as this ensures the cost-effective supply of power while satisfying the preferences of the consumers. The optimal operation of the energy hub is a complicated issue since it needs to consider both components constraints and costs. Hence, this paper focuses on the optimal operation of an energy hub that includes RES, PHEVs, FCVs, a hydrogen subsystem (an electrolyzer, a hydrogen tank, and a fuel cell), a boiler, an inverter, a rectifier, and a heat storage system under the uncertainty associated with the power consumption of PHEVs during trips using IGDT. 


\subsection{Literature review}

There is a rich literature for the optimal operation of renewable and sustainable energy systems. When an energy system consists of just one energy carrier, optimal operation is less complicated as it does not consider the interdependency between different forms of energy. Various studies have shown how a single energy carrier system can be optimized using a variety of different computational techniques for realizing sustainable development objectives. An algorithm for the optimal scheduling of a grid-connected micro-grid is investigated by Fossati et al. [27]. The micro-grid includes a wind turbine (WT), a battery bank, a micro-turbine, a diesel generator, and a fuel cell, which has a bilateral power exchange with the upstream power grid. The authors have employed two genetic algorithms (GAs) to perform the economic optimization and scheduling of the micro-grid. One of them tunes the membership functions for a fuzzy expert system used for controlling the output power of the battery bank, while the other calculates the optimal day-ahead scheduling of the micro-grid. Based on the simulation results, they have concluded that their algorithm achieves satisfactory results in both the grid-connected and islanded modes. Optimization model predictive framework for the reliable energy management of a grid-connected micro-grid with wind power generation system and a battery bank is developed by Prodan and Zio [28]. Based on the simulation results and comparisons using numerical data for a test system, the authors conclude that their method can efficiently optimize the objective function and contribute to significant operational cost savings. A nonlinear predictive energy management strategy for a residential building with a rooftop photovoltaic (PV) system and a battery energy storage system is investigated by Sun et al. [29]. In this paper, the authors focus on the fundamental trade-off between battery aging and the economic performance of the energy management strategy. Based on the results, they claim their proposed control system achieves $96-98 \%$ of the optimal performance given perfect meteorological and load forecasts over a long-term horizon.

In comparison with a single carrier energy system, an energy hub has a more complex system since it needs to work with various energy carriers. A stochastic model for optimal scheduling of a smart energy hub is presented by Dolatabadi and Mohammadi-Ivatloo [18] that includes combined heat and power (CHP) units, auxiliary boilers, a WT, a battery bank, and a thermal storage system. The authors consider electricity and natural gas as the primary energy carriers in their system. Using Monte Carlo simulation method, they consider the uncertainties associated with the wind power generation and load demand. Vahid-Pakdel et al. [30] study the optimal operation of an energy hub in the presence of electricity and thermal energy markets. Using Monte Carlo simulation method, they address the uncertainties associated with the market price, energy demand and wind speed. The authors conclude that the simultaneous implementation of a thermal energy market and a demand response program can reduce the operational cost by up to $4.8 \%$.

Several researchers have addressed the optimal operation of renewable energy systems through the coordinated management and uptake of PHEVs. Hota et al. [31] discuss the main issues of PHEV integration into the smart power systems and propose solutions for how they can be overcome. The optimal operation of micro-grids in the presence of PHEVs is also investigated by Bahramara et al. [1], where a two-stage robust optimization model is developed. In the first stage, trading with the upstream grid is addressed while in the second stage, the optimal scheduling of microgrids' resources is calculated. The authors satisfy the robustness of the model using two penalty factors that are included within the objective function. Similarly, an optimal energy management approach for home appliances commitment in the presence of PHEV and energy storage system is established by Sattarpour et al. [32]. Based on the numeric studies, the authors have deduced that the integration of energy storage systems and PHEVs into the proposed system reduces the energy payment cost of home owners and flattens the load profile. Kamankesh et al. [33] go further and develop a new stochastic framework based on the modified symbiotic organisms search (MSOS) optimization algorithm to study the energy management of micro-grids including RES, PHEVs, and storage devices considering the uncertainty associated with the PHEVs charging start time using Monte Carlo simulations. Based on the simulation results on two test systems, the authors have claimed that their proposed method is superior to a number of other famous methods in the area including the GA and particle swarm optimization (PSO). In another study, Wu et al. [34] devise an optimization framework to efficiently manage the operation of a grid-tied smart home nano-grid incorporating plug-in electric vehicles. By developing a convex programming control architecture for the home-tovehicle and vehicle-to-home modes, they have eliminated the need for buying electricity from the upstream grid during high electricity price time windows. Wu et al. [35] go further and propose a stochastic dynamic programming modeling 
framework for the optimal energy management of a smart home integrating plug-in electric vehicles. The authors have specifically focused on the uncertainty associated with vehicle energy storage and considered the vehicle plug-in time, plug-out time, and charge required for mobility as uncertain parameters. Based on the simulation results, the authors conclude that variable mobility patterns considerably affect the optimal scheduling behavior and result in significant operational cost savings. Thomas et al. [36] have put forward a mixed-integer linear programming model to optimize the energy management of an on-grid micro-grid equipped with a number of distributed energy resources, while taking into account a stochastic electric vehicles' driving schedule. The authors have considered the arrival times, detention times, and the initial state of energy levels of employed electric vehicles as uncertain variables and assigned them appropriate probability density functions in order to characterize their uncertainty. Their results confirm that adopting a stochastic approach in modeling the electric vehicles' driving schedule can substantially reduce the daily operational cost of the system. Aliasghari et al. [37] have investigated the optimal operation problem of an RES-based micro-grid, while considering the charging pattern of plug-in electric vehicles as a stochastic variable. The authors have demonstrated the capability of plug-in electric vehicles' charging management in reducing the daily system cost estimation by up to $40 \%$. Moghaddas-Tafreshi et al. [38] have also put forward a probabilistic unit commitment model to optimally operate plug-in electric vehicles in a grid-tied micro-grid serving both electrical and thermal loads. The authors have presented a scenario-based approach to cope with the uncertainties associated with the availability of vehicles, load demand prediction, and wind speed forecast. Based on the numeric simulation results, the authors have affirmed the superiority of their proposed model over a deterministic one in terms of reflecting the real-world practice.

In recent years there has been a growing interest in using IGDT to manage uncertain variables, while optimally operating the renewable and sustainable energy systems. The risk-based optimal operation of a PV-battery-fuel cell hybrid system whilst considering the uncertainty of the electrical load is analysed by Nojavan et al. [20]. The authors have investigated the effect of load uncertainty from positive and negative perspectives using robustness and opportunity functions of IGDT. According to their results, they demonstrate that under a risk-averse strategy, the energy hub operator pays a cost-penalty in order to purchase sufficient power from the upstream power network to increase the robustness of the system against the uncertainty of electrical load. On the other hand, by taking riskseeking strategy, the operator gains a cost-benefit. Similarly, the optimal performance of a grid-connected PV/fuel cell/ battery hybrid systems in the presence of a demand response program considering the electrical load uncertainty is evaluated by Nojavan et al. [21]. In this example, the authors use an IGDT to model the uncertainty associated with electrical load and shift a percentage of the load from peak to off-peak periods reducing the operational cost of the hybrid system by $2.97 \%$. The authors also model the load uncertainty using robustness and opportunity functions of IGDT enabling the system operator to make appropriate decisions to optimize the system against possible changes in load. The risk-based operation of an apartment smart building that includes a CHP generator, a boiler, a battery bank, a thermal storage system, and smart appliances is discussed by Najafi-Ghalelou et al. [39]. The authors solve their model from both risk-averse and risk-seeking perspectives by applying both robustness and opportunity functions of IGDT so that it is capable of handling the uncertainty associated with upstream grid price. Based on the simulation results, the authors demonstrate that the operational cost of the simulated building increases by $26.18 \%$ under the riskaverse strategy and by taking a risk-seeking strategy can increase its economic profit by $56.92 \%$. Mehdizadeh et al. [40] simulate a short term generation schedule for a grid-connected micro-grid in a day-ahead market in the presence of a demand response program. The model considers the uncertainty associated with upstream grid price using IGDT. Based on the simulation results, the authors conclude that their proposed IGDT-based modeling reduces the operational cost of the micro-grid by $4.6 \%$. Soroudi et al. [41] propose a novel method based on IGDT to evaluate a profitable operational strategy for electrical distribution systems with high wind penetration aiming at handling the wind power generation uncertainty, whilst minimizing the operational costs of the system. By examining their model on the IEEE 118-bus test system, the authors have demonstrated the efficacy of their method in dealing with the wind power generation volatility, while optimally operating an electrical power distribution grid. Najafi-Ghalelou et al. [42] present the risk-based scheduling of an smart home, which incorporates a solar thermal storage system considering the uncertainty associated with electricity price using the IGDT. Based on the simulation results, they have affirmed that their proposed method reduces the operational cost of a smart home by up to $13.67 \%$. Javadi et al. [43] propose a robust optimization framework utilizing the IGDT for coping with the load uncertainty for energy hub management. Based on the numerical simulation results, the authors have demonstrated the positive impacts of their framework on operational costs reduction for energy hubs. Dolatabadi et al. [44] go further and propose a hybrid stochastic/IGDT 
optimization method for the optimal scheduling of an energy hub aiming at minimizing its expected operational cost considering the uncertainties associated with wind power generation, electricity price, and energy demands. As the IGDT method is not capable of modeling more than one uncertain parameter at the same time, the authors only model the uncertainty associated with electricity price using the IGDT, while considering three sets of scenarios for modeling the uncertainties associated with wind power generation as well as electrical and thermal loads on the system. Based on the simulation results, they have proved the usefulness of their hybrid stochastic/IGDT model in tackling the most important uncertainties within their proposed energy hub.

The aforementioned papers together with many other research works not referred here have provided valuable contributions to the optimal operation of renewable and sustainable energy systems and in particular, energy hubs. The review of the literature identifies recent trends in modeling various uncertainties associated with energy hubs operation concentrating on the use of IGDT for uncertainty management. However, no one to the best of the authors' knowledge has studied the potential benefits of considering the uncertainty associated with power consumption of PHEVs during trips, while optimally operating any forms of renewable and sustainable energy systems. This is important as it paves the way towards reflecting the real-world practice in a more accurate manner in the day-ahead optimal energy management phase of renewable and sustainable energy systems, when accompanied by the identification of other more significant risk factors. Therefore, the aim of this study is to broaden the current state of knowledge of applying the IGDT method for handling uncertainties associated with operational variables of energy hubs as well as proposing an energy hub structure integrating two different types of green vehicles, which contributes to the goals of sustainable development.

\subsection{Contributions}

This article contributes a novel method for the optimal operation of a grid-connected energy hub that includes RES, PHEVs, FCVs, a hydrogen subsystem, a boiler, an inverter, a rectifier, and a heat storage system. Specific novelties within this method include:

- Modeling the uncertainty associated with the power consumption of PHEVs during trips using the IGDT method under both risk-averse and risk-seeking strategies.

- Providing incentives to PHEV owners in the form of discounted electricity rates, motivated by [45]. This enables us to predict the behavior of PHEVs.

- Integration of the FCVs into the energy hub. As FCVs consume hydrogen, this is in line with the multi-carrier nature of the energy hubs.

\subsection{Outline of paper}

The rest of this paper is organized as follows. Section 2 describes the proposed energy hub. In section 3 , the uncertainty modeling of PHEVs using IGDT is presented. In section 4, the formulation of the problem is presented. Section 5 presents the numerical simulation results. Finally, the conclusion of this study is presented in section 6 .

\section{System description}

The proposed energy system in this paper includes wind and solar energy sources, PHEVs, FCVs, an inverter, a rectifier, a hydrogen subsystem, a boiler, and a heat storage system as part of an energy hub as shown in Fig. 1. The proposed energy hub has bilateral energy exchange with the upstream power grid. Also, it is connected to the gas network for supplying a portion of the heat demand through dedicated boilers. Inputs into the energy hub include electricity supplied by the RES and the upstream electricity grid, as well as natural gas supplied by the upstream gas network. Conditional outputs of the energy hub include (1) electricity production that must meet the electrical demands of the system; (2) surplus power that is sold to the upstream grid; (3) the production of hydrogen that is used to meet the hydrogen demands of the FCVs; and, (4) the production of thermal hot water to meet the heating demands of buildings. In this system, PHEVs are operated in both of the vehicle-to-grid and grid-to-vehicle modes and FCVs are supplied using a hydrogen storage tank. Also, the hydrogen in the hydrogen tank can be used to produce electricity and heat by the fuel cell. Due to variations in the price of natural gas during the operation of the energy hub, the heat that is produced by the boiler or recovered from the fuel cell can be stored in the hot water tank, which is considered as the heat storage system of the energy hub. Moreover, the heat load can be supplied by boiler, heat storage, and heat recovery of fuel cell through the use of a heat exchanger. 


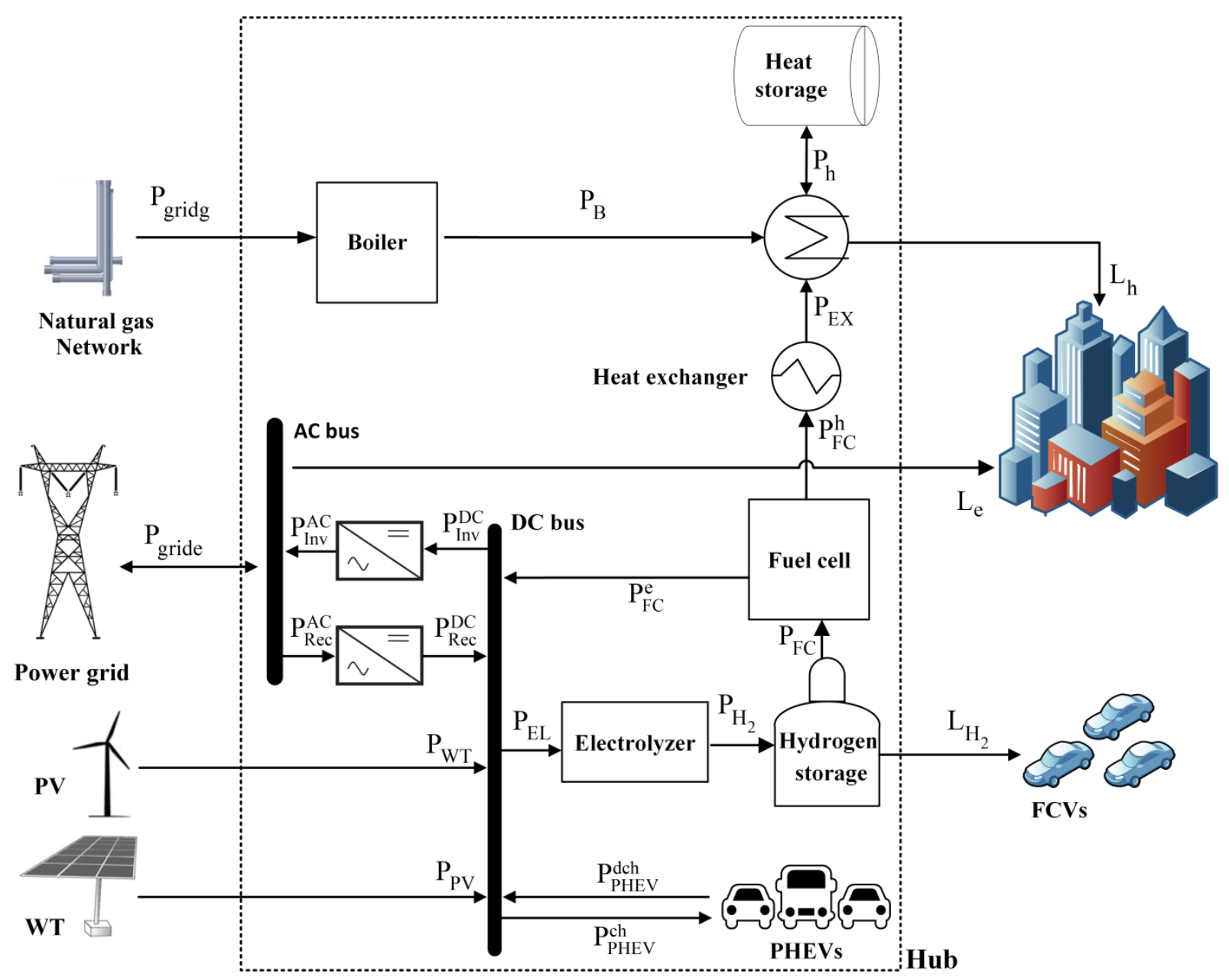

Fig. 1. Energy hub architecture.

\section{Uncertainty model}

In this paper, it is assumed that PHEVs are used only for commuting from home to work and other small inner city trips. Outside main driving hours, the PHEVs are connected to the grid either at home or at work and the bilateral energy exchange with energy hub is possible. Thus, these vehicles will be connected to the DC bus of the energy hub in a distributed manner. In this paper, the system operator is assumed to be the PHEVs' aggregator and a financial incentive is taken into account to attract the participation of vehicle owners in system operation. The incentive provided to PHEV owners is a $90 \%$ discount on their electricity purchases. In order to receive this discount, PHEV owners must announce their intention to buy and sell electricity on a day-ahead basis to the system operator and are required to plug-in their PHEVs as soon as they get home and leave plugged in while the car is parked. It is therefore assumed the system operator has full day-ahead information on the number of cars that will be connected to the network. The stored energy in each of the PHEVs' batteries is modeled according to the following equation:

$$
E_{V}(t)=E_{V}(t-1)+\eta_{V} P_{V}^{c h}(t) \Delta t-\frac{1}{\eta_{V}} P_{V}^{d c h}(t) \Delta t-P_{V}^{c o n s}(t) \Delta t
$$

where $\eta v$ is the energy consumption of the $\mathrm{V}^{\text {th }}$ PHEV per kilometer $[\mathrm{kWh} / \mathrm{km}] ; P_{V}^{c h}(t)$ and $P_{V}^{d c h}(t)$ are the charging and discharging powers of the $\mathrm{V}^{\text {th }}$ PHEV at time step $t[\mathrm{~kW}]$, respectively; $P_{V}^{c o n s}(t)$ denotes the power consumption of the $\mathrm{V}^{\text {th }}$ PHEV at time step $t[\mathrm{~kW}]$, which depends on the energy consumption per kilometer and average speed of the vehicle at time step $t$ that can be calculated according to Eq. (2); and $\Delta t$ is the length of each time step that is taken to be 1 hour in this study. 


$$
P_{V}^{\text {cons }}(t)=\eta_{V} V_{V}(t) Z_{V}(t) \Delta t
$$

where $V_{V}(t)$ denotes the average driving speed of the $\mathrm{V}^{\text {th }} \mathrm{PHEV}$ at time step $t[\mathrm{~km} / \mathrm{h}]$ and $Z_{V}(t)$ is a binary variable, which is equal to 1 if the PHEV is plugged out and equal to 0 if it is plugged in. It is worthwhile noting that from the perspective of PHEVs' batteries model, the power consumption of each PHEV's battery at time step $t$ can also be expressed as follows:

$$
P_{V}^{c o n s}(t)=\frac{\operatorname{Cap}_{V} \times\left(\operatorname{SOC}_{V}(t-1)+\operatorname{SOC}_{V}(t)-\operatorname{SOC}_{V}(0)\right)}{\Delta t},
$$

where $\operatorname{Cap}_{V}$ represents the rated capacity of the V $\mathrm{V}^{\text {th }} \mathrm{PHEV}$ 's battery $[\mathrm{kWh}], S O C_{V}(t)$ denotes the state of charge (SOC) of the $\mathrm{V}^{\text {th }}$ PHEV's battery at time step $t$ [\%], and $S O C_{V}(0)$ is the initial SOC of the $\mathrm{V}^{\text {th }}$ PHEV's battery, which is considered to be $90 \%$ in this study. The SOC can be defined as an indicator of the remaining energy content of a battery, which can be determined by dividing the remaining capacity of the battery at each time-step by its maximum energy storage capacity [46], [47].

Each PHEV has its own behavior and it is assumed that the owner of each PHEV informs the system operator about its intended future behavior ignoring uncertainty. When the PHEV is connected to the grid, the amount of stored energy in the battery is dispatchable. Also, when the PHEV is traveling and is not connected to the network, the power consumption of the PHEV is stochastic and therefore subject to a level of uncertainty, which is not considered in the announcements of PHEV owners to the system operator.

In this paper, it is assumed that the amount of predicted power consumption of each PHEV is available on a day-ahead basis and its uncertainty is modeled using the IGDT method. In the IGDT method, the range of error can be calculated according to the following equation [24]:

$$
P_{V}^{c o n s}(1-\alpha) \leq P_{V}^{c o n s} \leq P_{V}^{c o n s}(1+\alpha)
$$

where $\alpha$ is a number between 0 and 1 . The designed stochastic model is expressed in both risk-averse and risk-seeking strategies. The risk-averse strategy considers the critical profit as input and provides the maximum acceptable error in predicting the power consumption for each PHEV as an output, by maximizing the magnitude of change of undesirable power consumption from the predicted values for each PHEV. This model can be defined by the following equation [24]:

$$
\hat{\alpha}\left(P r_{c}\right)=\max _{\alpha}\left\{\alpha: \min (P r) \geq P r_{c}\right\}
$$

where $\hat{\alpha}\left(P r_{c}\right)$ is the robustness function, which indicates the maximum acceptable error in predicting the power consumption of each PHEV, $P r$ indicates the system profit to which IGDT method is applied, and $P r_{c}$ is the critical profit, which can be defined by the following equation [24]:

$$
P r_{c}=\left(1-\delta_{1}\right) P r_{d},
$$

where $\delta_{1}$ is the risk-averse deviation factor between 0 and 1 that represents the amount of risk-aversion of the decision and $\operatorname{Pr}_{d}$ denotes the deterministic profit. A large value for $\delta_{1}$ means that a more risk-averse decision is taken and $\operatorname{Pr}_{c}$ $\rightarrow 0$.

The risk-seeking model considers the desired target profit as input and provides the minimum acceptable error in predicting the power consumption of each PHEV as output through minimizing the range of change of the desirable power consumption of the PHEV based on the predicted values. This model can be defined by the following equation [24]:

$$
\hat{\beta}\left(P r_{w}\right)=\min _{\alpha}\left\{\alpha: \max (P r) \geq P r_{w}\right\}
$$

where $\hat{\beta}\left(P r_{w}\right)$ is the opportunity function, which indicates the minimum acceptable error in predicting the power consumption of each PHEV and $P r_{w}$ is the target profit, which can be expressed as Eq. (8). 


$$
P r_{w}=\left(1+\delta_{2}\right) P r_{d}
$$

where $\delta_{2}$ is the risk-seeking deviation factor between 0 and 1 that represents the amount of risk-seeking of the decision that its larger value means that a more risk-seeking decision is taken.

\section{Problem Formulation}

The problem is formulated under three risk strategies, namely the risk-neutral, risk-averse, and risk-seeking strategies. Each strategy will be described in the following sub-sections.

\subsection{Risk-neutral formulation}

In this strategy, the objective function is to maximize the profit in a 24-hour period under several constrains. This function can be expressed according to the following equation:

$\operatorname{Pr}_{d}$

$$
\begin{aligned}
& =\max \left(\sum _ { t = 1 V = 1 } ^ { 2 4 } \sum _ { V = 1 } ^ { 5 0 } \left(0.1 \pi^{e}(t) P_{V}^{c o n s}(t)+\pi^{e}(t) P_{\text {gride }}^{S}(t)+\pi^{g}(t) L_{h}(t)+\pi^{e}(t) L_{e}(t)+\pi^{e}(t) L_{H_{2}}(t)-\pi^{e}\right.\right. \\
& \left.\left.(t) P_{\text {gride }}^{B}(t)-\pi^{g}(t) P_{\text {gridg }}(t)\right)\right) .
\end{aligned}
$$

The objective function contained in Eq. (9) consists of seven parts including the income from supplying the required charging demand of PHEVs $\left(0.1 \pi^{e}(t) P_{V}^{c o n s}(t)\right)$, income from selling the electricity to the upstream power grid $\left(\pi^{e}(t)\right.$ $P_{\text {gride }}^{S}(t)$ ), income from supplying the required energy of the heat load $\left(\pi^{g}(t) L_{h}(t)\right)$, income from supplying the required energy of the electrical load $\left(\pi^{e}(t) L_{e}(t)\right)$, income from supplying the required hydrogen demands of the FCVs $\left(\pi^{e}(t) L_{H_{2}}(t)\right)$, cost of purchasing electricity from the upstream power grid $\left(\pi^{e}(t) P_{\text {gride }}^{B}(t)\right)$, and cost of purchasing gas from the upstream gas network $\left(\pi^{g}(t) P_{\text {gridg }}(t)\right)$.

The demand-supply balance equations that incorporate the terms governing conversion of energy carriers and operation of storage units can be formulated by Eqs. (10)-(12). The demand-supply balance for electrical power within the AC and DC buses can be described by Eqs. (10) and (11), respectively. The demand-supply balance for heat power is also described by Eq. (12).

$$
\begin{gathered}
P_{\text {gride }}(t)+L_{e}(t)+P_{R e c}^{A C}(t)=P_{I n v}^{A C}(t) \\
P_{I n v}^{D C}(t)+P_{E L}(t)+P_{P H E V}^{c h}(t)=P_{W T}(t)+P_{P V}(t)+P_{F C}^{e}(t)+P_{P H E V}^{d c h}(t)+P_{R e c}^{D C}(t) \\
L_{h}(t)+P_{h}^{c h}(t)={ }_{\eta B} P_{\text {gridg }}(t)+\eta E X P_{F C}^{h}(t)+P_{h}^{d c h}(t)
\end{gathered}
$$

where $P_{\text {gride }}$ is the energy hub's exchanged electrical power with the upstream power grid; $L_{e}$ is the electrical load power on the energy hub; $P_{R e c}^{A C}$ and $P_{R e c}^{D C}$ are the $\mathrm{AC}$ and DC powers of rectifier, respectively; $P_{I n v}^{A C}$ and $P_{I n v}^{D C}$ are the $\mathrm{AC}$ and DC powers of inverter, respectively; $P_{E L}$ is the power delivered from DC bus to the electrolyzer; $P_{P H E V} c h$ and $P_{P H E V}^{d c h}$ are the total charging and discharging powers of PHEVs, respectively; $P_{W T}$ is the output power of wind turbines; $P_{P V}$ is the output power of PV panels; $P_{F C}^{e}$ and $P_{F C}^{h}$ are the electrical and thermal output powers of the fuel cell, respectively; $L_{h}$ is the thermal load power on the energy hub; $P_{h}^{c h}$ and $P_{h}^{d c h}$ are the charging and discharging powers of heat storage system, respectively; $\eta B$ is the boiler efficiency; $P_{\text {gridg }}$ is the purchased power from the natural gas network; and $\eta E X$ is the heat exchanger efficiency.

The amount of energy stored in the hydrogen tank storage and heat storage system at each time step $t$ can be calculated by Eqs. (13) and (14), respectively.

$$
E_{H_{2}}(t)=E_{H_{2}}(t-1)+\eta H_{2} P_{H_{2}}(t) \Delta t-\frac{1}{\eta H_{2}}\left(P_{F C}(t)+L_{H_{2}}(t)\right) \Delta t
$$




$$
E_{h}(t)=E_{h}(t-1)+\eta_{h} P_{h}^{c h}(t) \Delta t-\frac{1}{\eta h} P_{h}^{d c h}(t) \Delta t
$$

where $\eta \mathrm{H}_{2}$ is the hydrogen tank efficiency, $P_{\mathrm{H}_{2}}$ is the power delivered from the DC bus to the electrolyzer, $P_{F C}$ is the power delivered from the hydrogen tank to the fuel cell, $L_{H_{2}}$ is the hydrogen load power on the energy hub, and $\eta h$ denotes the efficiency of the thermal storage system.

The total charging and discharging powers of PHEVs at time step $t$ can be expressed by Eqs. (15) and (16), respectively.

$$
\begin{gathered}
P_{P H E V}^{c h}(t)=\sum_{V=1}^{N} P_{V}^{c h}(t), \\
P_{P H E V}^{d c h}(t)=\sum_{V=1}^{N} P_{V}^{d c h}(t) .
\end{gathered}
$$

Considering the radiation intensity of the PV panels, the output power of PV panels at time step $t$ can be calculated according to the following equation [48]:

$$
P_{P V}(t)=\eta^{P V} N_{P V} A_{P V} G_{t}(t)
$$

where $\eta P V$ is the efficiency of PV panels, $N_{P V}$ is the number of panels, $A_{P V}$ is the area of a single panel [ $\left.\mathrm{m}^{2}\right]$, and $G_{t}$ $(t)$ is the total solar radiation incident on the tilted panel at time step $t\left[\mathrm{~W} / \mathrm{m}^{2}\right]$.

The output power of the wind power generation system at time step $t$ can be described in terms of wind speed by the following equation [49]:

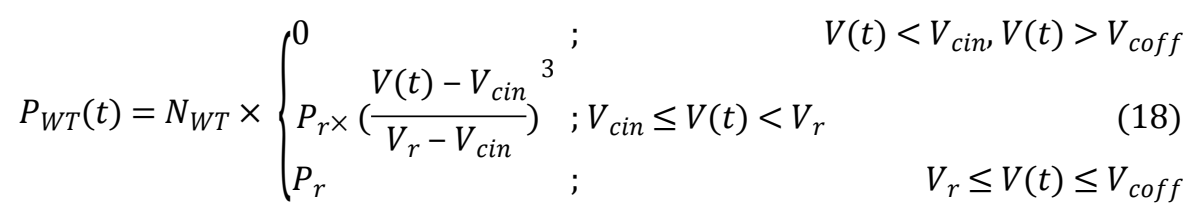

where $V_{c i n}, V_{c o f f}$, and $V_{r}$ denote the cut-in, cut-off, and nominal wind speeds, respectively that are considered to be $2.5,25$, and $11 \mathrm{~m} / \mathrm{s}$, respectively; $V(t)$ is the wind speed at time step $t ; N_{W T}$ is the number of wind turbines; and $P_{r}$ is the rated power of each wind turbine, which is considered to be $7.5 \mathrm{~kW}$ in this project.

Some of the constraints of the system for conversion, storage and exchange of electricity with the upstream power grid, and receiving natural gas from the upstream gas network are expressed by Eqs. (19)-(25).

$$
\begin{gathered}
0 \leq P_{V}^{c h}(t) \leq P^{c h, \max _{V}} X_{V}(t), \\
0 \leq P_{V}^{d c h}(t) \leq P_{V}^{d c h \max } Y_{V}(t), \\
0 \leq E_{V}(t) \leq E_{V}^{\max }, \\
E_{H_{2}}^{\min } \leq E_{H_{2}}(t) \leq E_{H_{2}}^{\max }, \\
E_{h}^{\min } \leq E_{h}(t) \leq E_{h}^{\max }, \\
\left|P_{\text {gride }}(t)\right| \leq P_{\text {gride }}^{\max },
\end{gathered}
$$




$$
0 \leq P_{\text {gridg }}(t) \leq P_{\text {gridg }}^{\max }
$$

where $P^{c h, \max _{V}}$ and $P^{d c h \text { max }}$ are the maximum charging and discharging powers of the battery of the $\mathrm{V}^{\text {th }}$ PHEV [kW], respectively; $E_{V}^{\max }$ is the maximum allowable capacity of the battery of the $\mathrm{V}^{\text {th }} \mathrm{PHEV}[\mathrm{kWh}] ; E_{H_{2}}^{\min }$ and $E_{H_{2}}^{\max }$ are the minimum and maximum allowable capacities of the hydrogen tank [kWh], respectively; $E_{h}^{\min }$ and $E_{h}^{\max }$ are the

minimum and maximum allowable capacities of the heat storage system $[\mathrm{kWh}]$, respectively; $P_{\text {gride }}^{\max }$ is the maximum capacity of the power line connected between the energy hub and upstream power grid $[\mathrm{kW}] ; P_{\text {gridg }}^{\max }$ is the maximum capacity of the natural gas pipeline connected between the energy hub and upstream natural gas network [kW]; $X_{V}$ is a binary variable, which is equal to 1 if the PHEV is charging and equal to 0 if it is not charging; and $Y_{V}$ is a binary variable, which is equal to 1 if the PHEV is discharging and equal to 0 if it is not discharging.

In addition to the above constraints, the output power of the electrolyzer and the fuel cell are constrained to be between zero and their rated power at each time step $t$. Furthermore, each PHEV at each time step $t$ can only ever be charging discharging or traveling according to Eq. (26).

$$
X_{V}(t) \cap Y_{V}(t) \cap Z_{V}(t) \leq 1
$$

\subsection{Robustness and opportunity objective functions}

The robustness and opportunity objective functions for considering the uncertainty associated with power consumption of PHEVs during trips under the risk-averse and risk-seeking strategies can be calculated according to the following equations:

$\hat{\alpha}$

$$
\begin{aligned}
& =\max _{\alpha}\left(\sum _ { t = 1 } ^ { 2 4 } \sum _ { V = 1 } ^ { 5 0 } \left(0.1 \pi^{e}(t)(1+\alpha) P_{V}^{c o n s}(t)+\pi^{e}(t) P_{\text {gride }}^{S}(t)+\pi^{g}(t) L_{h}(t)+\pi^{e}(t) L_{e}(t)+\pi^{e}(t) L_{H_{2}}(t)-\pi^{e}(t)\right.\right. \\
& \left.\left.P_{\text {gride }}^{B}(t)-\pi^{g}(t) P_{\text {gridg }}(t)\right) \geq\left(1-\delta_{1}\right) P r_{d}\right) \text {, }
\end{aligned}
$$

$\hat{\beta}$

$$
\begin{aligned}
& =\min _{\alpha}\left(\sum _ { t = 1 } ^ { 2 4 } \sum _ { V = 1 } ^ { 5 0 } \left(0.1 \pi^{e}(t)(1-\alpha) P_{V}^{c o n s}(t)+\pi^{e}(t) \underset{\text { gride }}{S}(t)+\pi^{g}(t) L_{h}(t)+\pi^{e}(t) L_{e}(t)+\pi^{e}(t) L_{H_{2}}(t)-\pi^{e}(t)\right.\right. \\
& \left.\left.P_{\text {gride }}(t)-\pi^{g}(t) P_{\text {gridg }}(t)\right) \geq\left(1+\delta_{2}\right) P r_{d}\right) \text {. }
\end{aligned}
$$

\subsection{Solution methodology}

The deterministic objective function is formulated as a mixed-integer programming problem that can be solved using general algebraic modeling system (GAMS) software. The procedure of simulation is summarized as follows:

i. The deterministic objective function in Eq. (9) is maximized subject to the aforementioned constraints. The results include the maximum profit of the system operation and the optimal power flow of the energy hub.

ii. For various deviation values of profit, the robustness objective function in Eq. (27) is maximized subject to the aforementioned constraints. The results include the maximum deviation of the predicted power consumption of PHEVs and the optimal power flow of the energy hub.

iii. For various deviation values of profit, the opportunity objective function in Eq. (28) is minimized subject to the aforementioned constraints. The results include the minimum deviation of the predicted power consumption of PHEVs and the optimal power flow of the energy hub.

\section{Numerical simulation}

A numerical simulation is used to illustrate the optimal operation of the proposed energy hub that will be presented in the following sub-sections. 


\subsection{Input data}

The system parameters are presented in Table 1 [50]-[53]. It is assumed that there are 50 PHEVs in the system. For reasons of space, we classified the driving patterns of the 50 PHEVs into three main groups utilizing the k-means clustering method [54], and then randomly selected a representative sample of each group for in-depth analyses. The behavior of these 3 PHEVs in terms of traveling time between home and workplace and average driving speed is shown in Table 2. Furthermore, the detailed driving patterns of the fleet of 50 PHEVs are given as supplementary material accompanying the paper (Additional file 1: Table S1). In addition, the types and technical specifications of the selected PHEV brands in this study (i.e. the leading brands in the North American market) are detailed in Table 3 [55]. The table also reports the proportions of the considered PHEV types in the total fleet of 50 PHEVs. Also, the electrical loads (EL), thermal loads (TL), hydrogen loads (HL), solar radiation (SR), wind speed (WS), electricity price (EP), and natural gas price (GP) during 24 hours are shown in Table 4.

Table 1. System parameters [50]-[53].

\begin{tabular}{|c|c|c|c|c|c|c|c|}
\hline Parameter & Value & Parameter & Value & Parameter & Value & Parameter & Value \\
\hline$\eta V$ & $\begin{array}{c}0.1 \\
\mathrm{kWh} / \mathrm{km}\end{array}$ & $\eta \operatorname{Rec}$ & $90 \%$ & $\eta h$ & $90 \%$ & $\eta H_{2}$ & $95 \%$ \\
\hline$\eta P V$ & $18 \%$ & $\eta B$ & $85 \%$ & $\eta E X$ & $90 \%$ & $\eta F C$ & $50 \%$ \\
\hline$\eta E L$ & $90 \%$ & $\eta I n v$ & $90 \%$ & $N$ & 50 & $P_{\text {gride }}^{\max }$ & $80 \mathrm{~kW}$ \\
\hline$P^{c h, \max }$ & $\begin{array}{c}3.3,6.6 \\
\mathrm{~kW}\end{array}$ & $P^{d c h, \max }$ & $\begin{array}{c}3.3,6.6 \\
\mathrm{~kW}\end{array}$ & $A_{P V}$ & $1 \mathrm{~m}^{2}$ & $N_{P V}$ & 100 \\
\hline$N_{W T}$ & 10 & $V_{c u t-i n}$ & $3 \mathrm{~m} / \mathrm{s}$ & $V_{c u t-o f f}$ & $25 \mathrm{~m} / \mathrm{s}$ & $r_{F C}^{h}$ & 0.8 \\
\hline$P_{\text {gridg }}^{\max }$ & $50 \mathrm{~kW}$ & $P_{F C}^{\text {rated }}$ & $20 \mathrm{~kW}$ & $E_{V}^{\max }$ & $10 \mathrm{kWh}$ & $E_{H_{2}}^{\min }$ & $0 \mathrm{kWh}$ \\
\hline$E_{H_{2}}^{\max }$ & $200 \mathrm{kWh}$ & $E_{h}^{\min }$ & $0 \mathrm{kWh}$ & $E_{h}^{\max }$ & $200 \mathrm{kWh}$ & $P_{E L}^{\text {rated }}$ & $30 \mathrm{~kW}$ \\
\hline
\end{tabular}

Table 2. Typical behavior of the three of the PHEVs.

\begin{tabular}{cccccc}
\hline PHEV number & $\boldsymbol{t}_{\boldsymbol{l} \boldsymbol{h}}[\mathrm{h}]$ & $\boldsymbol{t}_{\boldsymbol{a} \boldsymbol{w}}[\mathrm{h}]$ & $\boldsymbol{t}_{\boldsymbol{l} \boldsymbol{w}[\mathrm{h}]}$ & $\boldsymbol{t}_{\boldsymbol{a} \boldsymbol{h}}[\mathrm{h}]$ & $\boldsymbol{V}_{\boldsymbol{V}}[\mathrm{km} / \mathrm{h}]$ \\
\hline 1 & 7 & 9 & 20 & 21 & 30 \\
25 & 7 & 8 & 15 & 17 & 35 \\
50 & 9 & 10 & 16 & 17 & 25 \\
\hline
\end{tabular}

Table 3. Types of selected PHEVs and their technical characteristics [55].

\begin{tabular}{cccc}
\hline PHEV brand & $\begin{array}{c}\text { Capacity of the } \\
\text { battery [kWh] }\end{array}$ & $\begin{array}{c}\text { Maximum on-board } \\
\text { charging/discharging } \\
\text { rate [kW] }\end{array}$ & $\begin{array}{c}\text { Share in the } \\
\text { fleet [\%] }\end{array}$ \\
\hline Chevrolet Volt & 14 & 3.3 & 40 \\
Toyota Prius Prime & 9 & 3.3 & 26 \\
Honda Accord Plug-in & 7 & 6.6 & 18 \\
Ford Fusion Energi & 7 & 3.3 & 16 \\
\hline
\end{tabular}


Table 4. Daily input data of the simulation.

\begin{tabular}{|c|c|c|c|c|c|c|c|}
\hline Hour & $\mathrm{EL}[\mathrm{kW}]$ & $\mathrm{TL}[\mathrm{kW}]$ & $\mathrm{HL}[\mathrm{kW}]$ & $\mathrm{SR}\left[\mathrm{kW} / \mathrm{m}^{2}\right]$ & $\mathrm{WS}[\mathrm{m} / \mathrm{s}]$ & $\mathrm{EP}[\$ / \mathrm{kWh}]$ & $\mathrm{GP}[\$ / \mathrm{kWh}]$ \\
\hline 1 & 0 & 0 & 0 & 0 & 0 & 27 & 18 \\
\hline 2 & 8.1 & 0 & 0 & 0 & 1 & 10 & 18 \\
\hline 3 & 4.5 & 0 & 0 & 0 & 0 & 23 & 18 \\
\hline 4 & 4.86 & 12.6 & 0 & 0 & 0 & 23 & 22 \\
\hline 5 & 8.1 & 16.2 & 0 & 0 & 1 & 26 & 26 \\
\hline 6 & 11.7 & 19.8 & 0 & 0.19 & 2 & 23 & 30 \\
\hline 7 & 18.9 & 37.8 & 0 & 0.41 & 4 & 27 & 35 \\
\hline 8 & 19.8 & 22.5 & 20 & 0.58 & 5 & 33 & 30 \\
\hline 9 & 23.4 & 19.8 & 20 & 0.63 & 4 & 34 & 27 \\
\hline 10 & 24.3 & 0 & 20 & 0.79 & 5 & 33 & 18 \\
\hline 11 & 25.2 & 0 & 0 & 1.02 & 6 & 34 & 18 \\
\hline 12 & 27.9 & 7.2 & 0 & 1.04 & 7 & 38 & 18 \\
\hline 13 & 28.8 & 10.8 & 0 & 1.03 & 6 & 34 & 25 \\
\hline 14 & 30.6 & 8.1 & 0 & 0.98 & 5 & 33 & 22 \\
\hline 15 & 29.7 & 7.2 & 0 & 0.89 & 6 & 33 & 10 \\
\hline 16 & 28.8 & 0 & 0 & 0.76 & 4 & 32 & 18 \\
\hline 17 & 28.8 & 0 & 0 & 0.53 & 5 & 32 & 18 \\
\hline 18 & 28.8 & 6.3 & 0 & 0.37 & 4 & 49 & 20 \\
\hline 19 & 28.8 & 15.3 & 10 & 0.2 & 2 & 47 & 25 \\
\hline 20 & 29.7 & 25.2 & 10 & 0.04 & 1 & 42 & 30 \\
\hline 21 & 21.6 & 15.3 & 10 & 0 & 1 & 39 & 25 \\
\hline 22 & 19.8 & 9.9 & 10 & 0 & 0 & 36 & 22 \\
\hline 23 & 17.1 & 0 & 0 & 0 & 0 & 34 & 18 \\
\hline 24 & 17.1 & 0 & 0 & 0 & 0 & 29 & 18 \\
\hline
\end{tabular}

\subsection{Simulation results and discussion under the risk-neutral strategy}

The proposed model under the risk-neutral strategy is simulated using the GAMS software. The optimal energy exchange between the system components on the AC and DC buses as well as thermal and hydrogen energy exchange under the deterministic strategy are shown in Fig. 2.

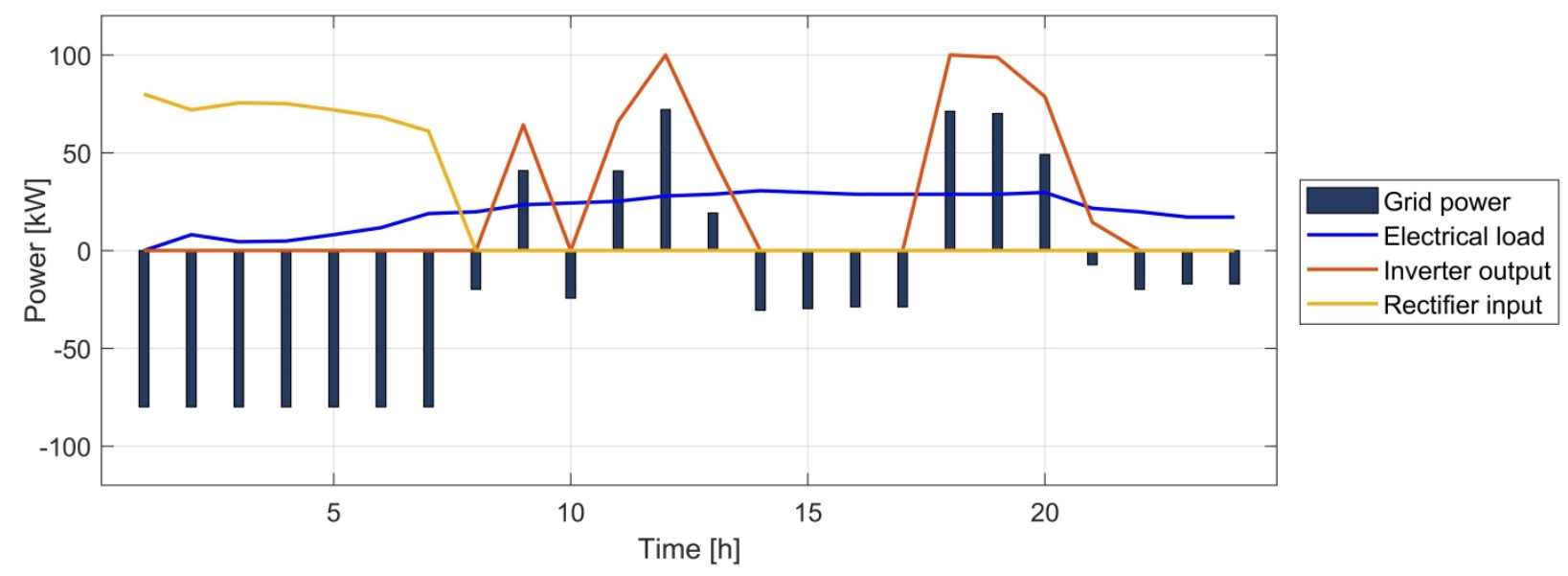

(a) 

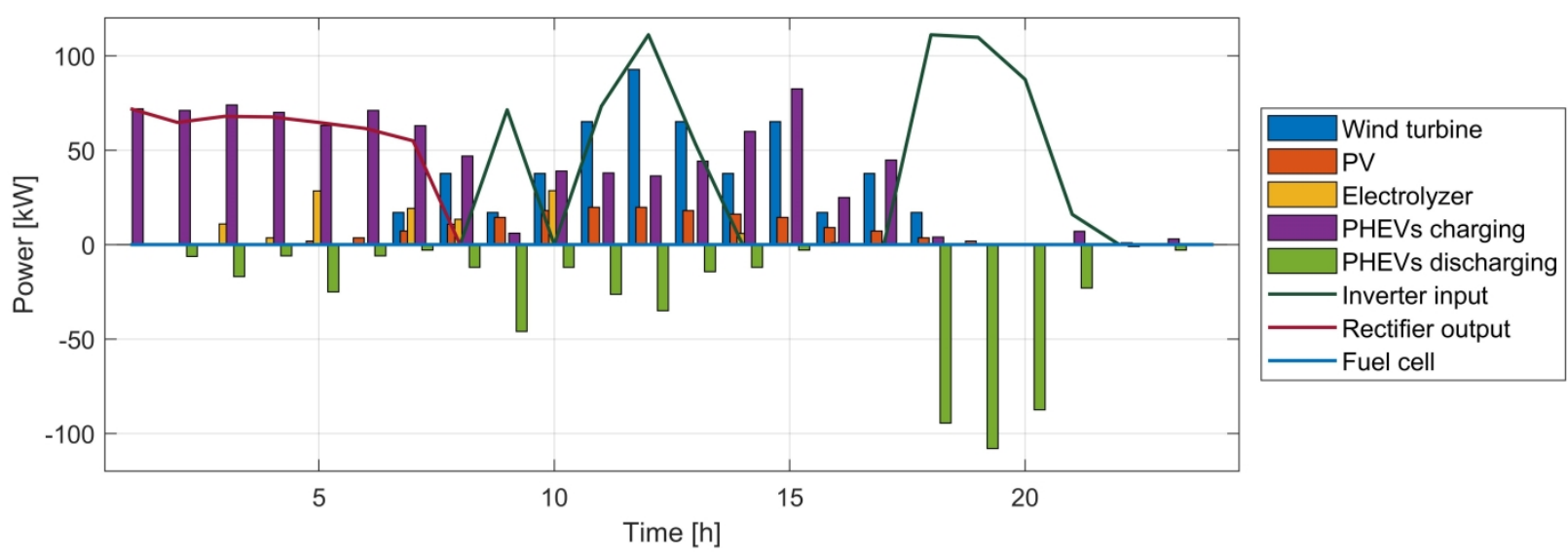

(b)

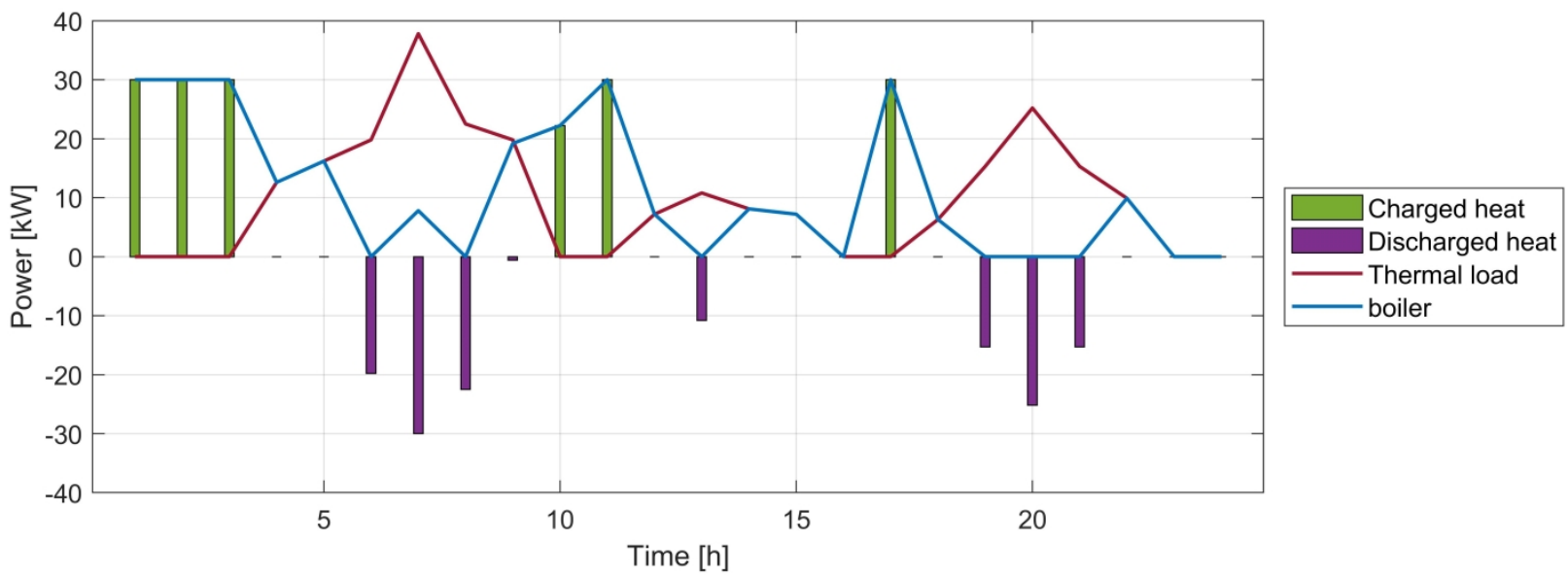

(c)

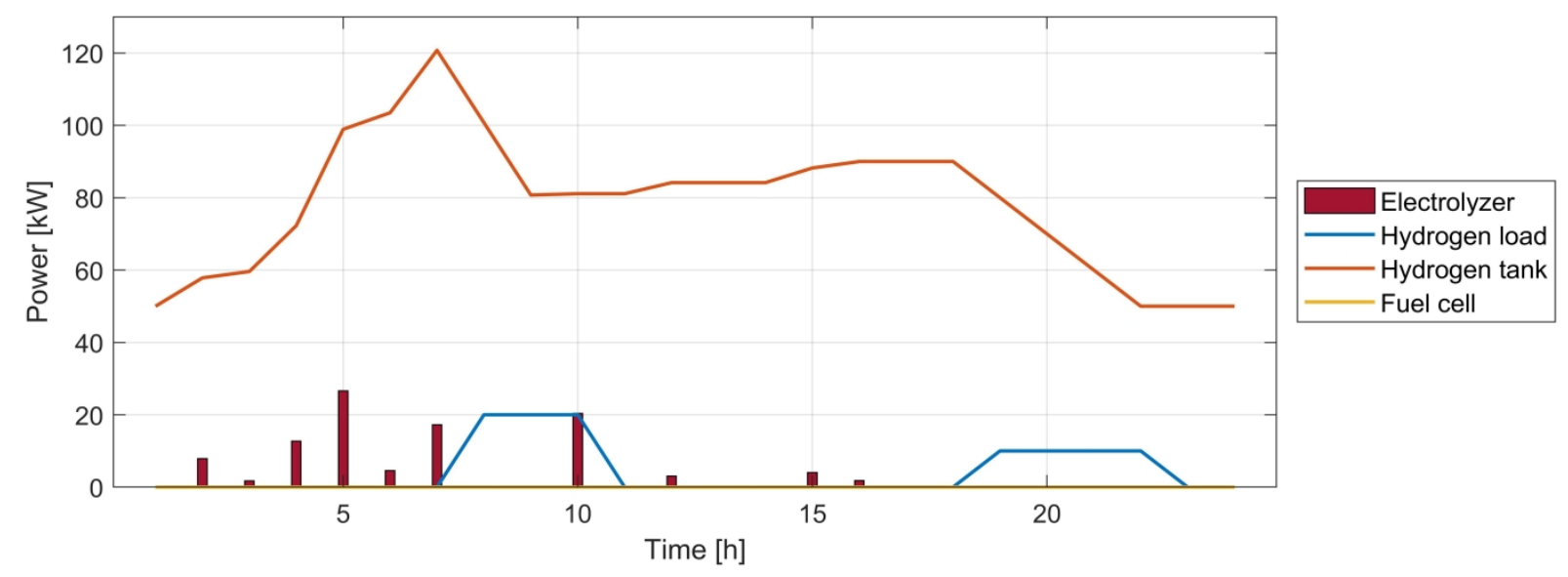

(d)

Fig. 2. Energy exchange under the risk-neutral strategy: (a) AC bus; (b) DC bus; (c) Heat; and (d) Hydrogen.

As can be seen in Fig. 2, during the first 7 hours of the day (light load hours) where the renewable power generation is approximately zero, almost all the required electrical power is purchased from the grid and it is distributed between the electrical loads and the components that are connected to the DC bus. Since most of the PHEVs are expected to disconnect from the grid at the $7^{\text {th }}$ hour, the distributed power to the DC bus during the first 7 hours is mostly allocated for charging the PHEVs. The power produced by RES during the $8^{\text {th }}-12^{\text {th }}$ hours are used for charging the PHEVs that 
require energy for traveling. Since the prices are relatively high in this period, the surplus of power produced by the renewable sources and discharging the PHEVs after meeting the demands of electrical loads and PHEVs are sold to the grid. At the $14^{\text {th }}$ hour, due to a relative reduction of the price, this trend has changed temporarily and the electrical loads are supplied by the grid and RES. At this hour, the power produced by discharging the PHEVs are used for charging the PHEVs that require energy for traveling. According to the disconnection of a majority of the PHEVs from the grid before the $18^{\text {th }}$ hour, the shortage of power production during the $14^{\text {th }}-17^{\text {th }}$ hours is purchased from the grid. The reason for the shortage of power production at these hours is that the PHEVs should be charged for departure at their corresponding hours. Then, from the $18^{\text {th }}$ hour onwards, due to the increased electricity prices and approximately zero renewable energy production, the energy is discharged from the PHEVs, first meeting internal electrical loads and then sold to the grid.

As can be seen in Fig. 2 , at the $1^{\text {st }}, 2^{\text {nd }}, 3^{\text {rd }}, 10^{\text {th }}, 11^{\text {th }}$, and $17^{\text {th }}$ hours, the gas price is relatively low. At these hours, the boiler not only satisfies the heat load but also generates extra heat for storage and future use. In the remaining hours, where the gas price is relatively high, the heat load is supplied by an optimal combination of discharging the heat storage system and operation of the boiler.

Due to the low electrical efficiency of the fuel cell and the variation of the electricity price at different hours, it can be seen from Fig. 2 that the fuel cell is not used to convert the hydrogen into electricity. Also, according to the low cost of natural gas storage and high efficiency of heat storage, the fuel cell is not used for heat generation purposes either.

As can be seen in Fig. 2, the energy stored in the hydrogen tank is equal to $50 \mathrm{kWh}$ at the beginning of the operation and it is assumed that it should not be less than this amount at the end of the operation. Due to the presence of a hydrogen load, and the relatively low price of electricity in the early hours, and the amount of renewable generation, the electrolyzer is operated during the $3^{\text {rd }}-10^{\text {th }}$ hours occasionally to increase the hydrogen energy stored in the tank. Since the operation of the fuel cell in this system is not profitable, the electrolyzer is only operated to supply the FCVs.

In this system, the charging and discharging of the PHEVs are managed so that optimal operation is realized. Accordingly, the operation of the PHEVs 1, 25 and 50 under this strategy are shown in Fig. 3.

According to Table 2, PHEV 1 is initially connected to the system, leaves home at the $7^{\text {th }}$ hour and arrives at the workplace at the $9^{\text {th }}$ hour and reconnects to the system. Therefore, the operation of this PHEV before the $7^{\text {th }}$ hour should be managed such that it would have the required energy for doing two hours of traveling. As shown in Fig. 3, this PHEV is charged during the $2^{\text {nd }}-7^{\text {th }}$ hours and its battery state of charge has increased. Due to a relative increase of electricity price at the $12^{\text {th }}$ hour, this PHEV is charged at the $10^{\text {th }}$ hour and discharged at the $12^{\text {th }}$ hour. This PHEV leaves the workplace at the $20^{\text {th }}$ hour and arrives at home at the $21^{\text {st }}$ hour and reconnects to the system. Therefore, the operation of this PHEV before the $20^{\text {th }}$ hour should be managed such that it would have the required energy for doing one hour of traveling. Also, due to a relative increase of the electricity price at the $18^{\text {th }}$ hour, this PHEV is charged before the $18^{\text {th }}$ hour and contributes to the system's profit by discharging and selling power to the grid during the $18^{\text {th }}$ $20^{\text {th }}$ hours. In the remaining hours, due to the continuous reduction of electricity prices, this PHEV has not been charged and discharged. This is because it would not be able to take advantage of lower prices by discharging and selling power to the grid due to the decreasing trend of the electricity prices. Another reason is that there is no constraint on the SOC of PHEV batteries at the end of the operational timeframe (i.e. 24 hours) in this study.

According to Table 2, the PHEV 25 is initially connected to the system, leaves home at the $7^{\text {th }}$ hour and arrives at the workplace at the $8^{\text {th }}$ hour and reconnects to the system. Therefore, the operation of this PHEV before the $7^{\text {th }}$ hour should be managed such that it would have the required energy for doing one hour of traveling. As shown in Fig. 3, this PHEV is charged at the $1^{\text {st }}$ hour and during the $3^{\text {rd }} 6^{\text {th }}$ hours and its battery state of charge has increased. This PHEV is discharged at the $2^{\text {nd }}$ hour to provide the energy for charging of other PHEVs. This PHEV leaves the workplace at the $15^{\text {th }}$ hour, arrives at home at the $17^{\text {th }}$ hour and reconnects to the system. Therefore, its operation before the $15^{\text {th }}$ hour should be managed such that it would have the required energy for doing two hours of traveling. Also, due to a relative increase of electricity price at the $18^{\text {th }}$ hour, this PHEV is charged before the $18^{\text {th }}$ hour and increases the system's profit by discharging and selling power to the grid during the $18^{\text {th }}-19^{\text {th }}$ hours. Furthermore, similar to the PHEV 1, this PHEV has not been charged and discharged in the remaining hours. 
According to Table 2, the PHEV 50 is initially connected to the system, leaves home at the $9^{\text {th }}$ hour and arrives at the workplace at the $10^{\text {th }}$ hour and reconnects to the system. Therefore, the operation of this PHEV before the $9^{\text {th }}$ hour should be managed such that it would have the required energy for doing one hour of traveling. As shown in Fig. 3, this PHEV is charged at the $1^{\text {st }}, 3^{\text {rd }}, 4^{\text {th }}, 7^{\text {th }}$, and $8^{\text {th }}$ hours and its battery state of charge increases. This PHEV is discharged at the $6^{\text {th }}$ hour to provide the energy for charging of other PHEVs. This PHEV leaves the workplace at the $16^{\text {th }}$ hour, arrives at home at the $17^{\text {th }}$ hour and reconnects to the system. Therefore, the operation of this PHEV before the $16^{\text {th }}$ hour should be managed such that it would have the required energy for doing one hour of traveling. Also, due to a relative increase of electricity price at the $18^{\text {th }}$ hour, this PHEV is charged before the $18^{\text {th }}$ hour and increases the system's profit by discharging and selling power to the grid during the $18^{\text {th }}-21^{\text {st }}$ hours. In the remaining hours, due to the decreasing trend of electricity prices and as there is no constraint on its SOC at the end of the operational timeframe, this PHEV has not been charged and discharged. It is worthwhile noting that the electricity prices are much cheaper in the early hours of the morning than the late night hours.

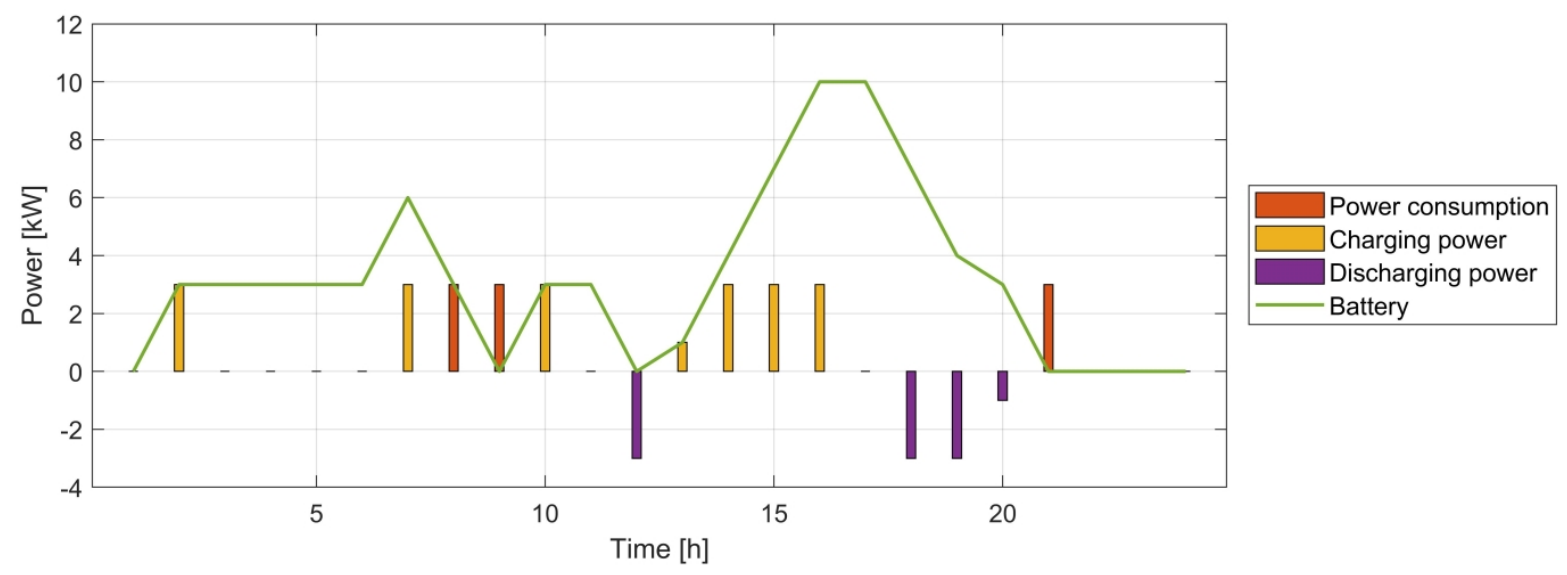

(a)

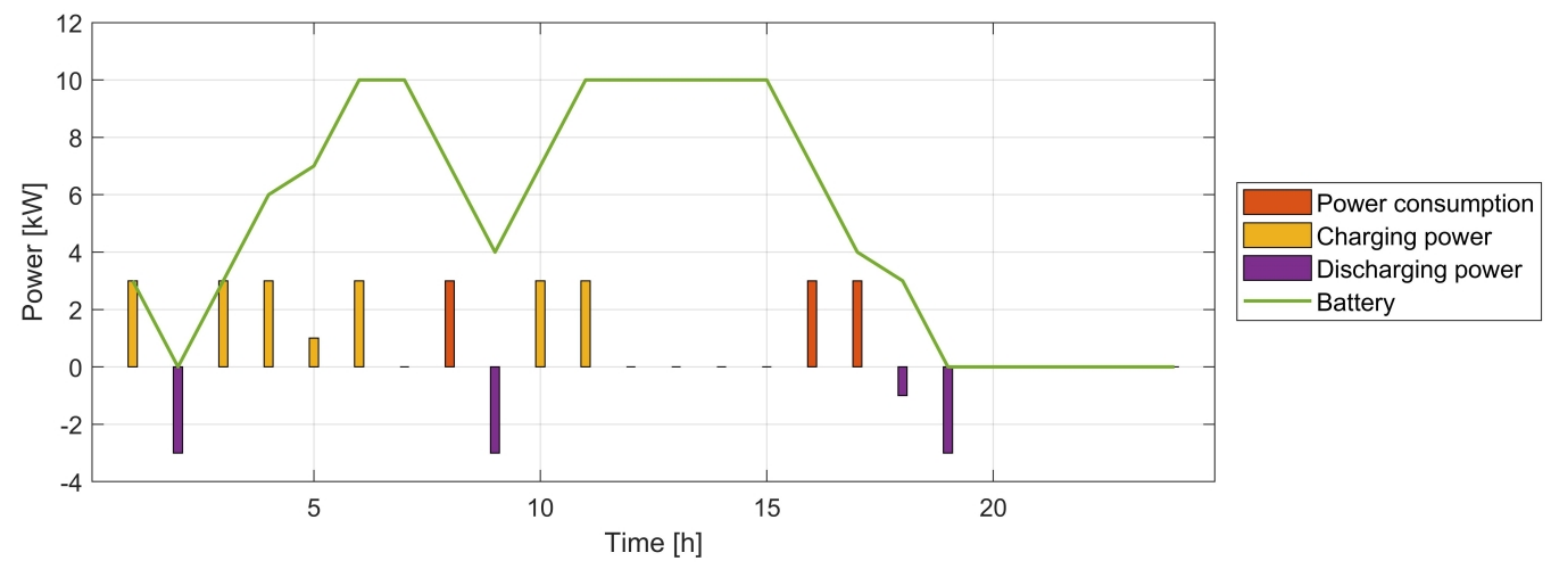

(b) 


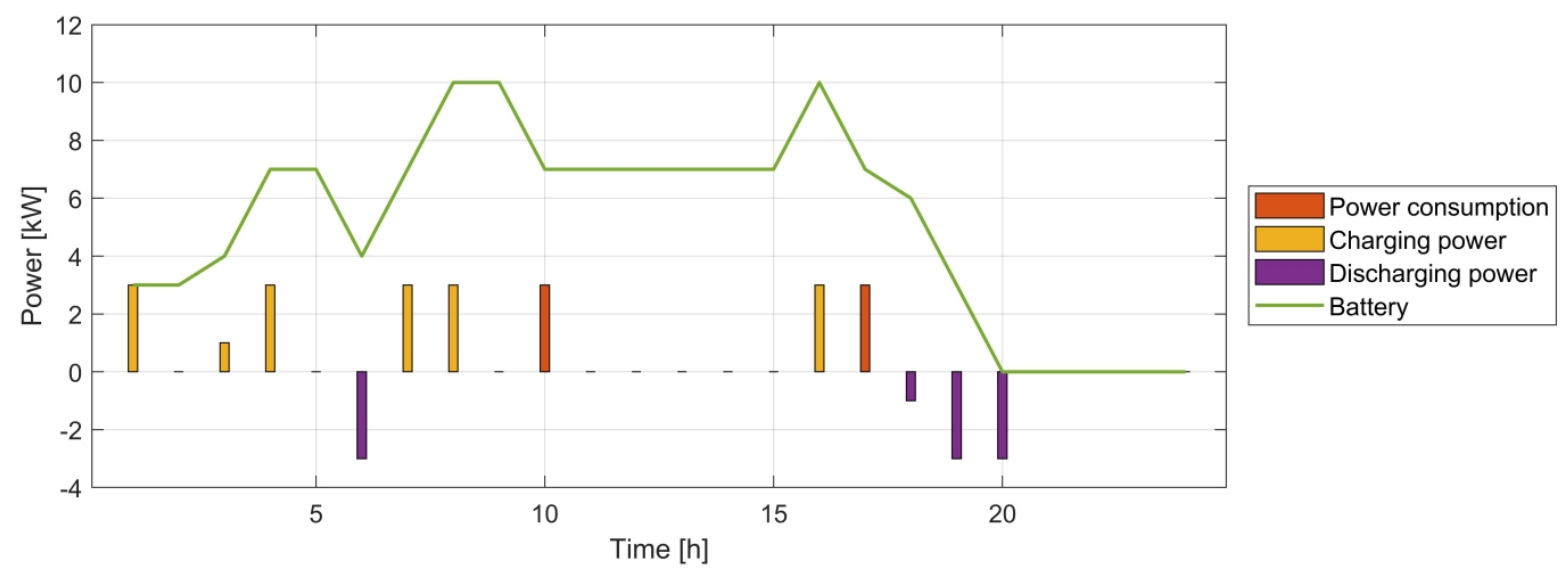

(c)

Fig. 3. Operating status of the considered PHEVs under the risk-neutral strategy: (a) PHEV 1; (b) PHEV 25; and (c) PHEV 50.

The profit of the system under this strategy is equal to $\$ 18,649$.

\subsection{Simulation results and discussion under the risk-averse strategy}

In order to simulate the system under the risk-averse strategy for handling the uncertainty associated with the power consumption of PHEVs, the values of $\delta_{1}$ are selected randomly and the robustness of the objective function is optimized under the considered constraints using the GAMS software. The obtained results show the maximum deviation from the predicted power consumption of PHEVs achieves a minimum profit that is greater than the critical profit.

The results of optimizing the robustness of the objective function for different values of $\delta_{1}$ are shown in Fig. 4 (a). This curve shows how much uncertainty in the predicted power consumption of PHEVs is tolerable in order to achieve a minimum profit of $\left(1-\delta_{1}\right) P r_{d}$. Note that in this figure, $\delta_{1}=0$ corresponds to the risk-neutral case where the critical profit is equal to the deterministic profit. According to Fig. 4 (a), as $\delta_{1}$ increases, the robustness parameter increases as well, which means a higher range of error in predicting the power consumption of PHEVs can be tolerated at the cost of lower profit expectations. For example, for the case of 10 and 70 percent less profit than the profit gained under the risk-neutral strategy, then $9.1 \%$ and $66.7 \%$ of error in the predicted power consumption of PHEVs can be tolerated, respectively. The PHEVs consume more power under the risk-averse strategy which is due to the lower profit of the system. Also, it is worth noting that because of the limited capacity of the PHEVs batteries, the power consumption of the PHEVs can only increase to the charge capacity of the battery.

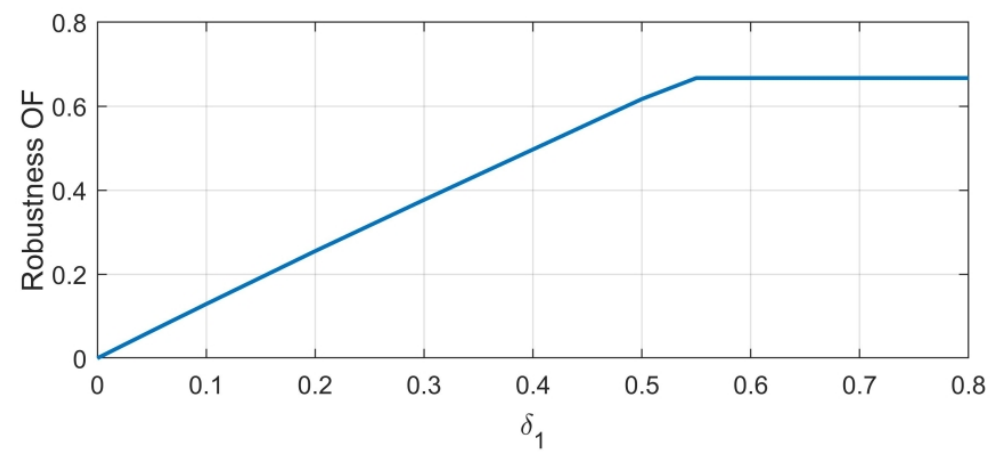

(a) 


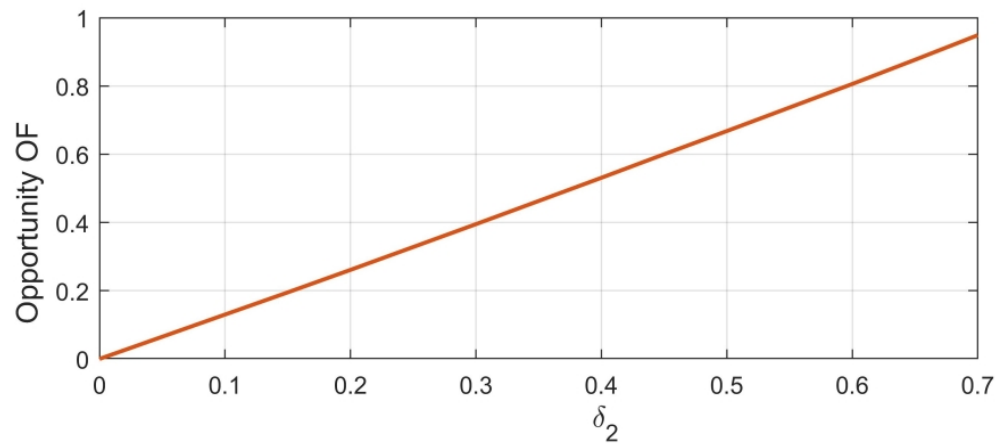

(b)

Fig. 4. Objective functions of the proposed IGDT method: (a) Robustness; and (b) Opportunity.

Under the risk-averse strategy, when the deviation factor of profit $\left(\delta_{1}\right)$ is equal to 0.4 , the critical profit will be equal to $\$ 11,189$ and the maximum deviation from the predicted amount of power consumption would be equal to 0.5 . The optimal energy exchange between the system components on the AC and DC buses as well as thermal and hydrogen energy exchange under the risk-averse strategy are shown in Fig. 5. The operation of the PHEVs 1, 25 and 50 under this strategy are also shown in Fig. 6.

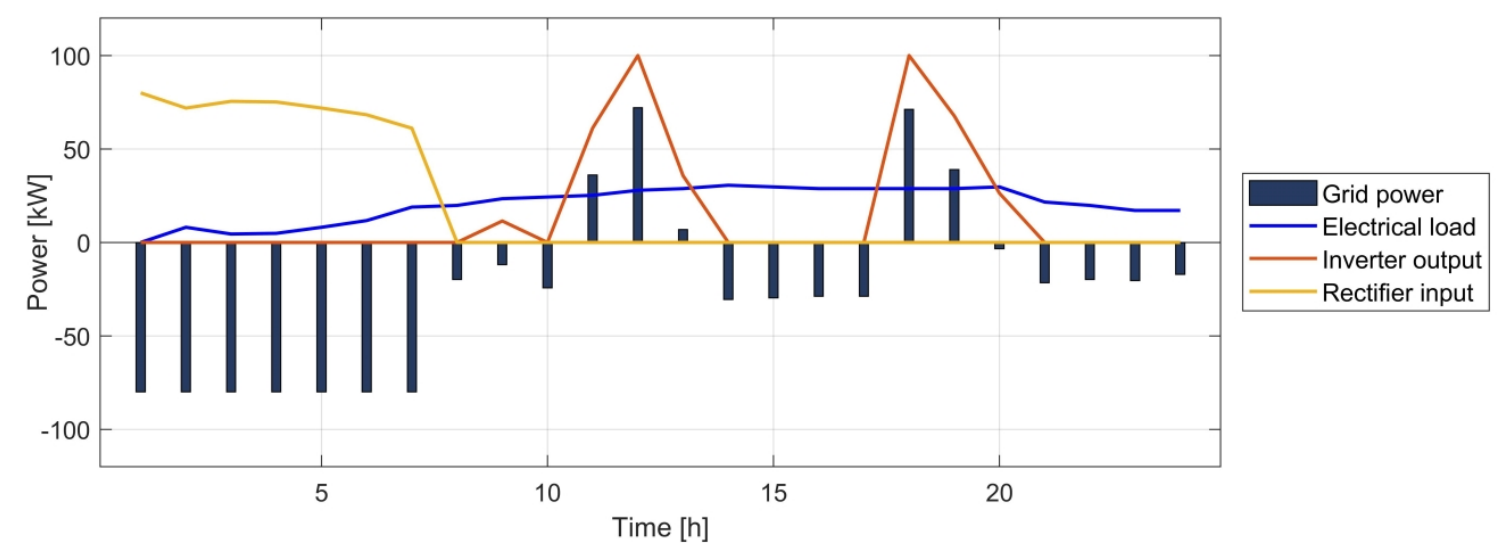

(a)

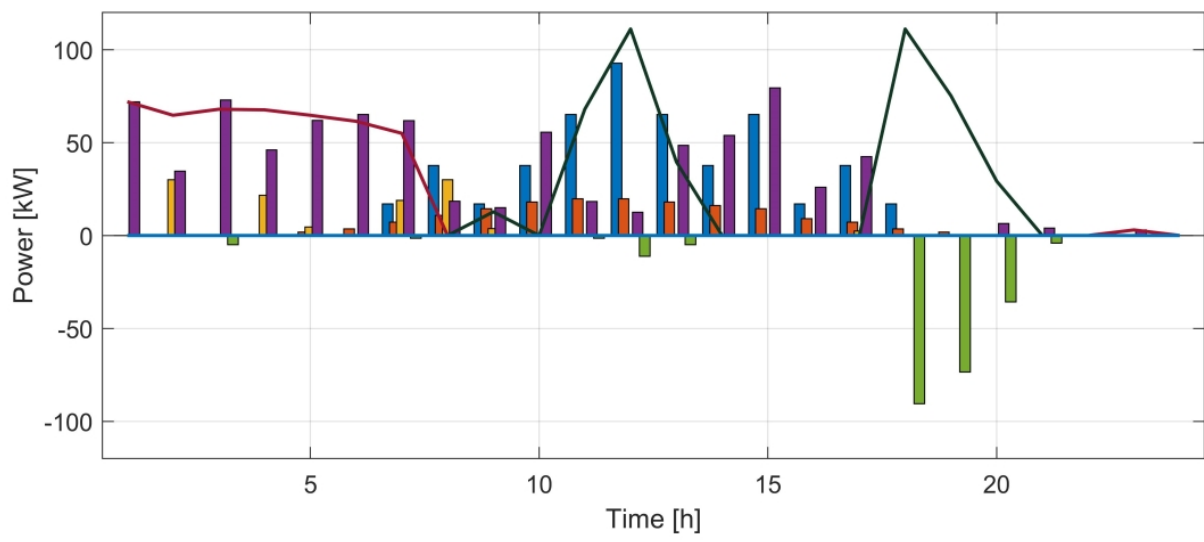

Wind turbine PV 


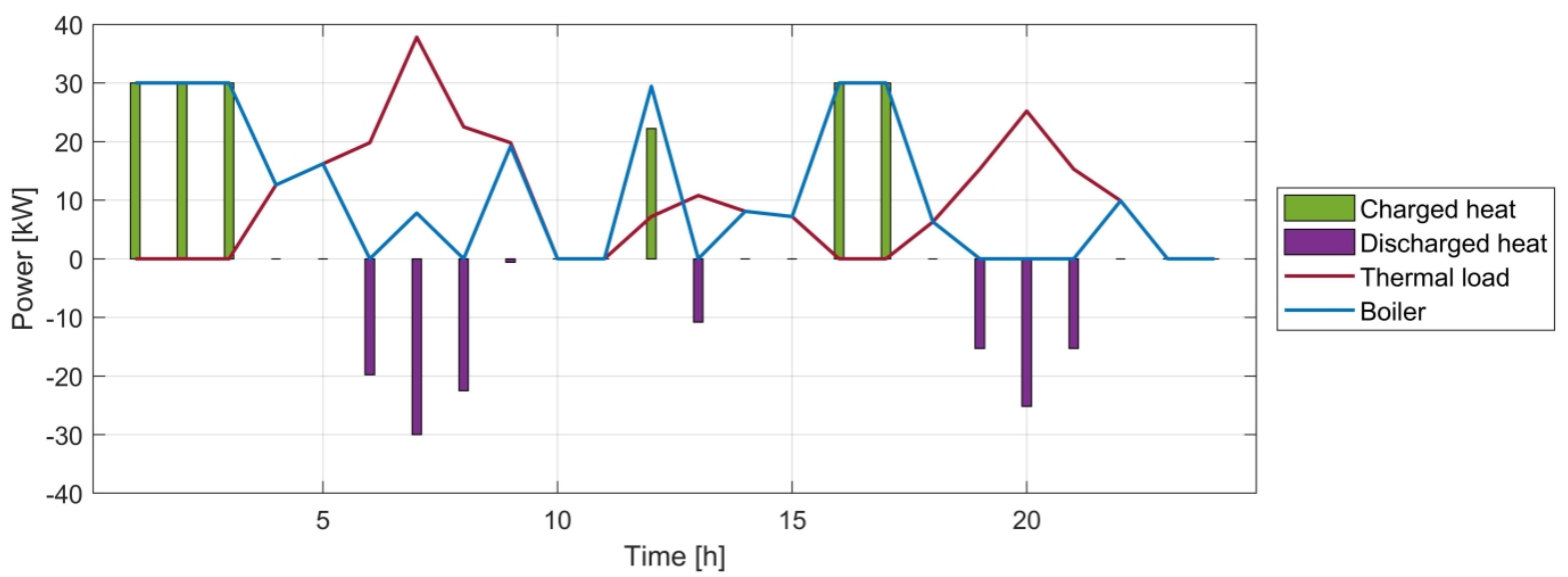

(c)

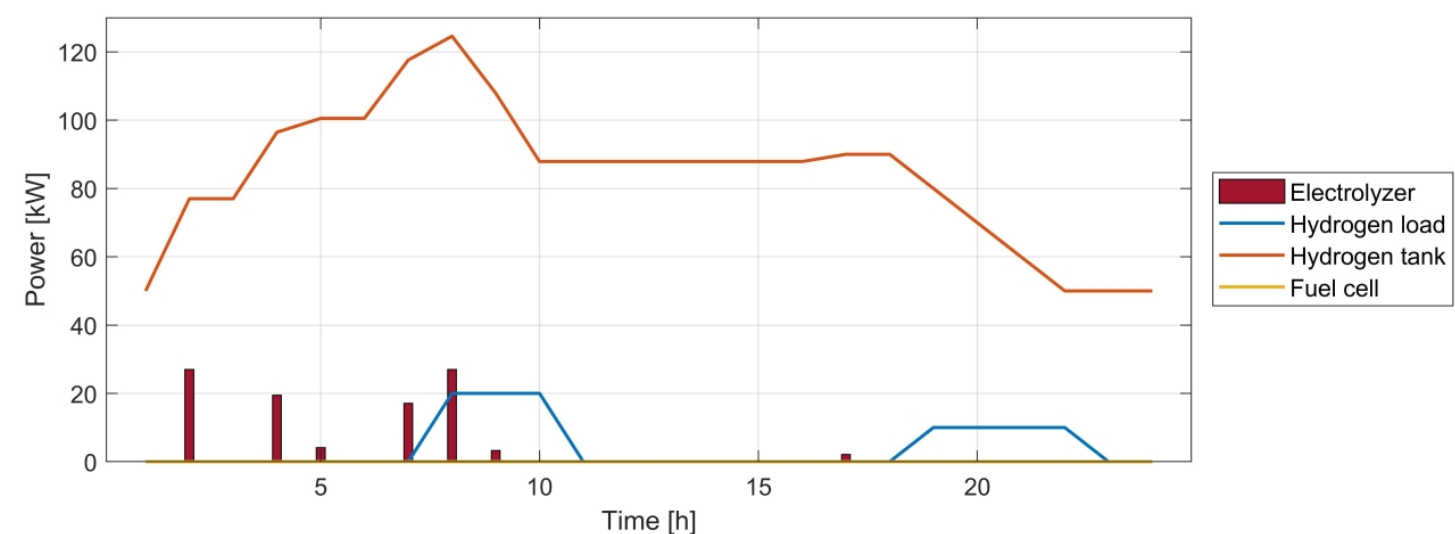

(d)

Fig. 5. Energy exchange under the risk-averse strategy: (a) AC bus; (b) DC bus; (c) Heat; and (d) Hydrogen. 

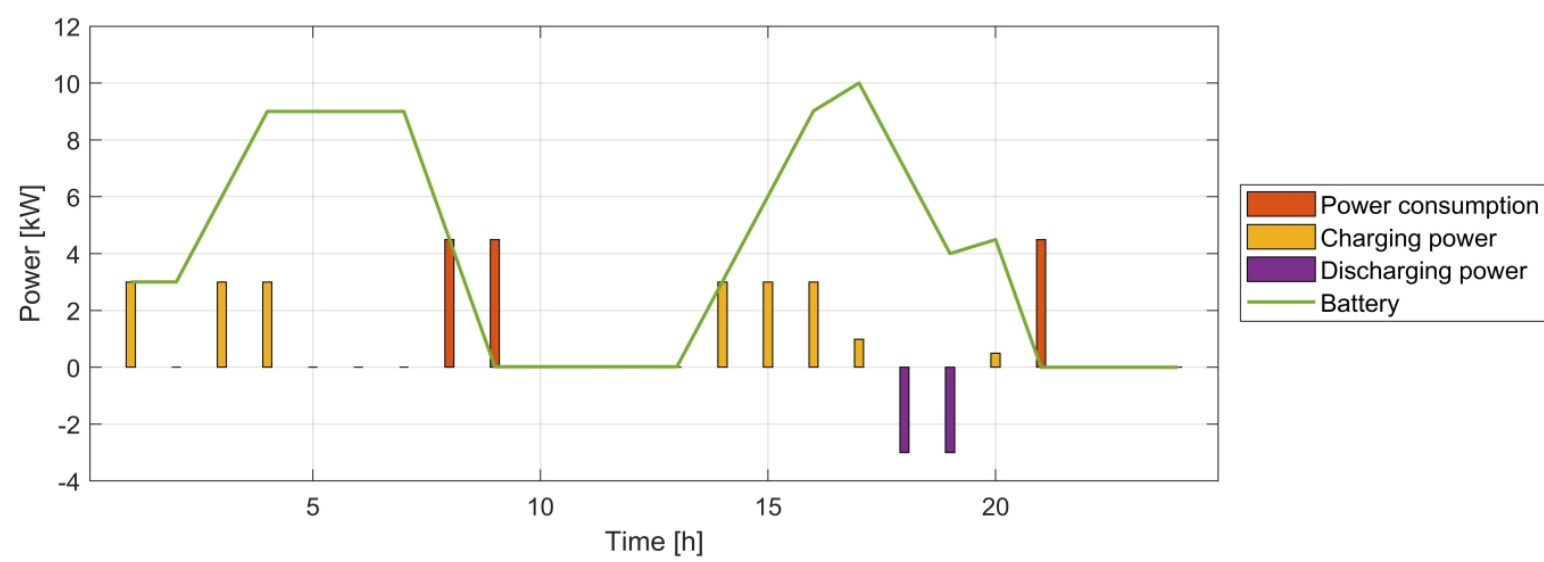

(a)
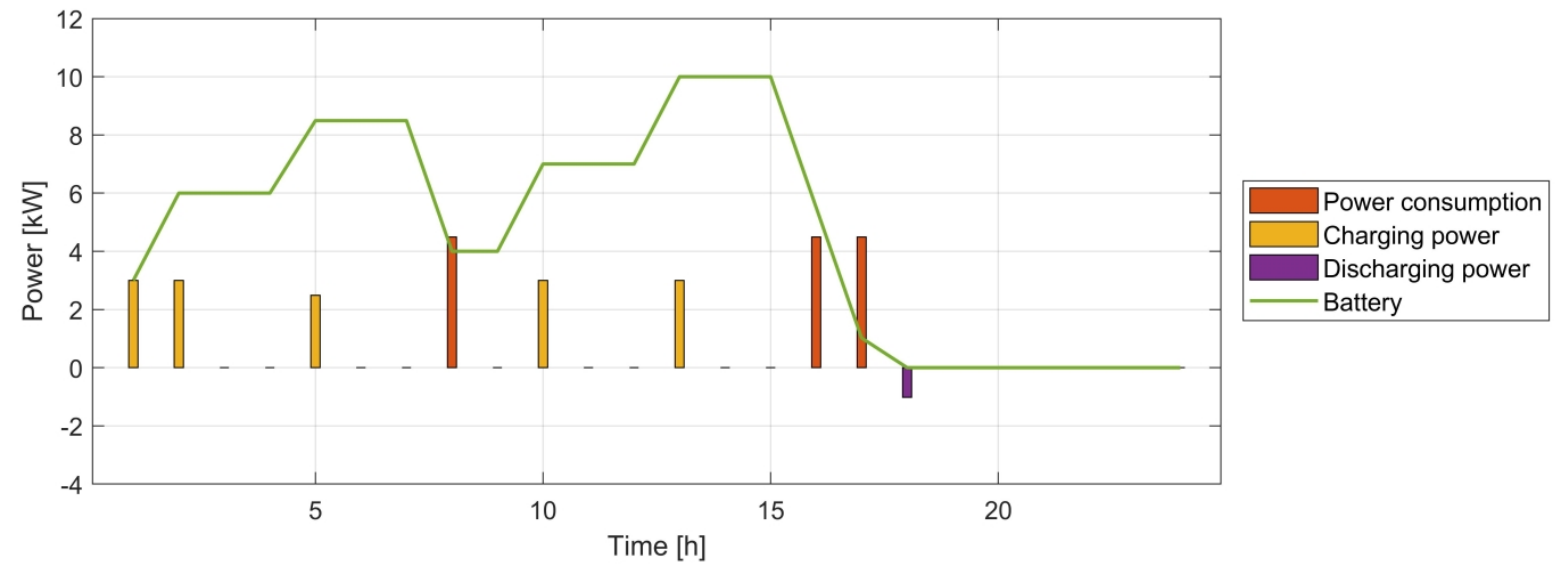

(b)

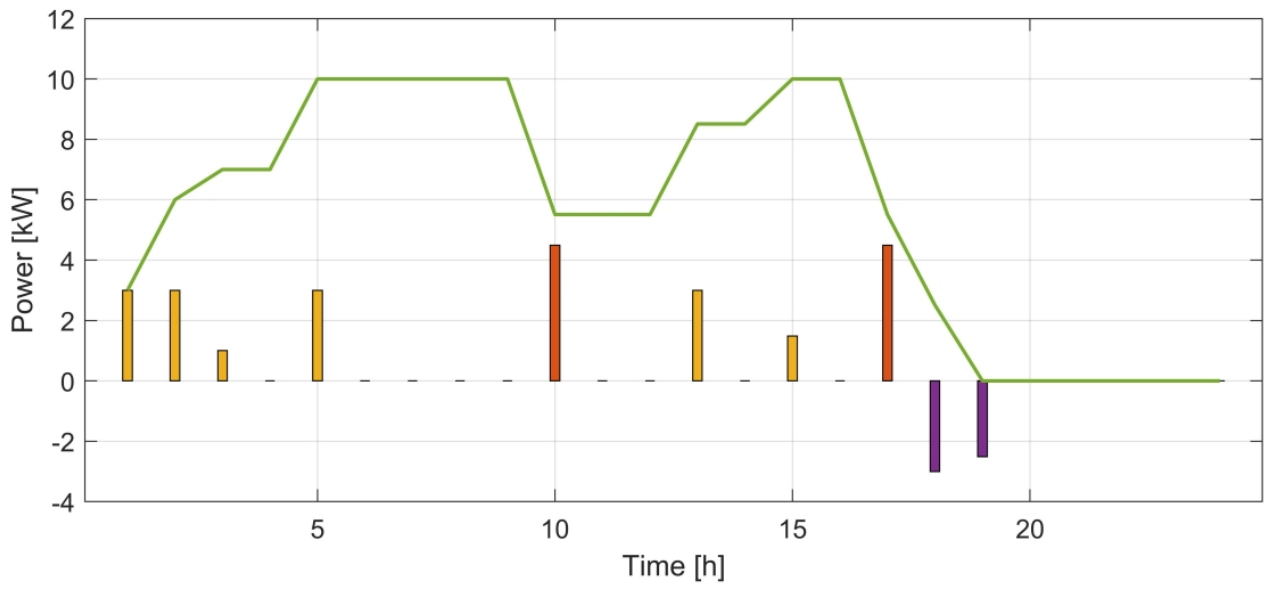

\begin{tabular}{|l|}
\hline Power consumption \\
\hline Charging power \\
Discharging power \\
\hline Battery \\
\hline
\end{tabular}

(c)

Fig. 6. Operating status of the considered PHEVs under the risk-averse strategy: (a) PHEV 1; (b) PHEV 25; and (c) PHEV 50.

Under this strategy, as the power consumption of PHEVs increases, the purchased electricity from the power grid also increases and the profit decreases. For example, by setting the critical profit at $\$ 13,420$ and solving the proposed robustness objective function using GAMS, the maximum deviation from the predicted amount of power consumption will be equal to 25.5 percent. If the power consumption increases, the profit will be less than the critical profit. Also, by increasing the power consumption of PHEVs, the total discharging power of PHEVs decreases and less power will 
be sold to the upstream power grid. As can be seen in Fig. 6, by increasing the power consumption of the PHEV 1, a lower amount of its energy is discharged. This is also true for the PHEVs 25 and 50.

\subsection{Simulation results and discussion under the risk-seeking strategy}

In order to simulate the system under the risk-seeking strategy for handling the uncertainty associated with the power consumption of PHEVs, the values of $\delta_{2}$ are selected randomly and the opportunity objective function is optimized under the constraints considered using GAMS software. The obtained results show the minimum deviation from the predicted power consumption of PHEVs for achieving a maximum profit that is greater than the target profit.

The results of optimizing the opportunity objective function for different values of $\delta_{2}$ are shown in Fig. 4 (b). This curve shows the minimum required uncertainty of the power consumption of PHEVs in order to have a certain maximum profit of $\left(1+\delta_{2}\right) P r_{d}$. According to Fig. 4 (b), a higher target profit requires higher deviations of the power consumption of PHEVs from the forecasted values. For example, for the case of 10 and 70 percent more profit than the profit under the risk-neutral strategy, 13 and 95 percent of error in the predicted power consumption of PHEVs is required, respectively.

Under the risk-seeking strategy, when the deviation factor of profit $\left(\delta_{2}\right)$ is equal to 0.4 , the target profit would be equal to $\$ 2,610$ and the minimum deviation from the predicted amount of power consumption would be equal to 0.53 . The optimal energy exchange between the system components on the AC and DC buses as well as thermal and hydrogen energy exchange under the risk-seeking strategy are shown in Fig. 7. Also, the operation of the PHEVs 1, 25 and 50 under this strategy are shown in Fig. 8.

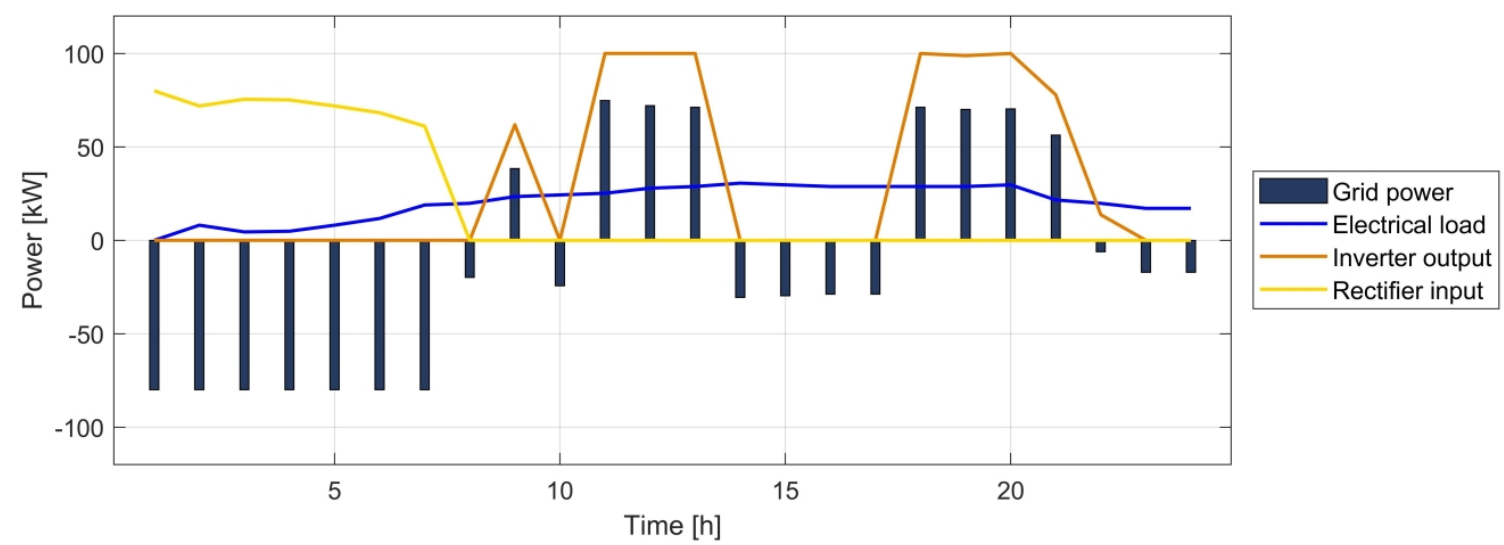

(a)

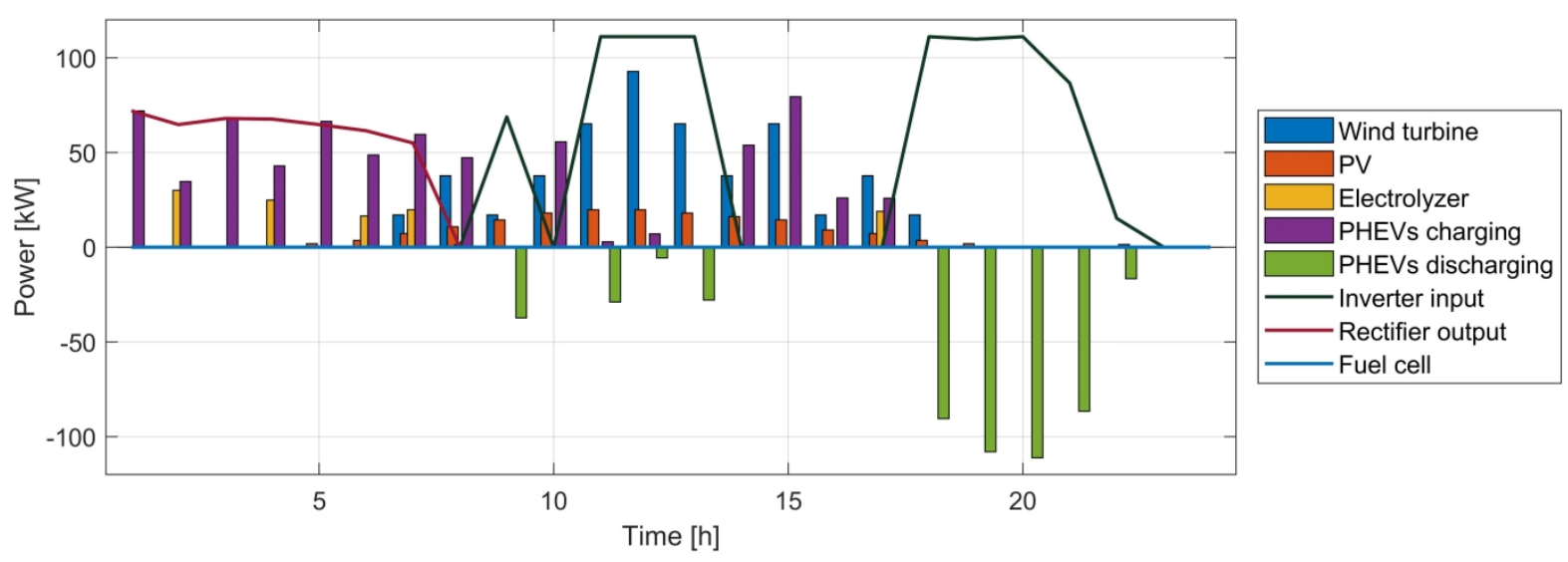

(b) 


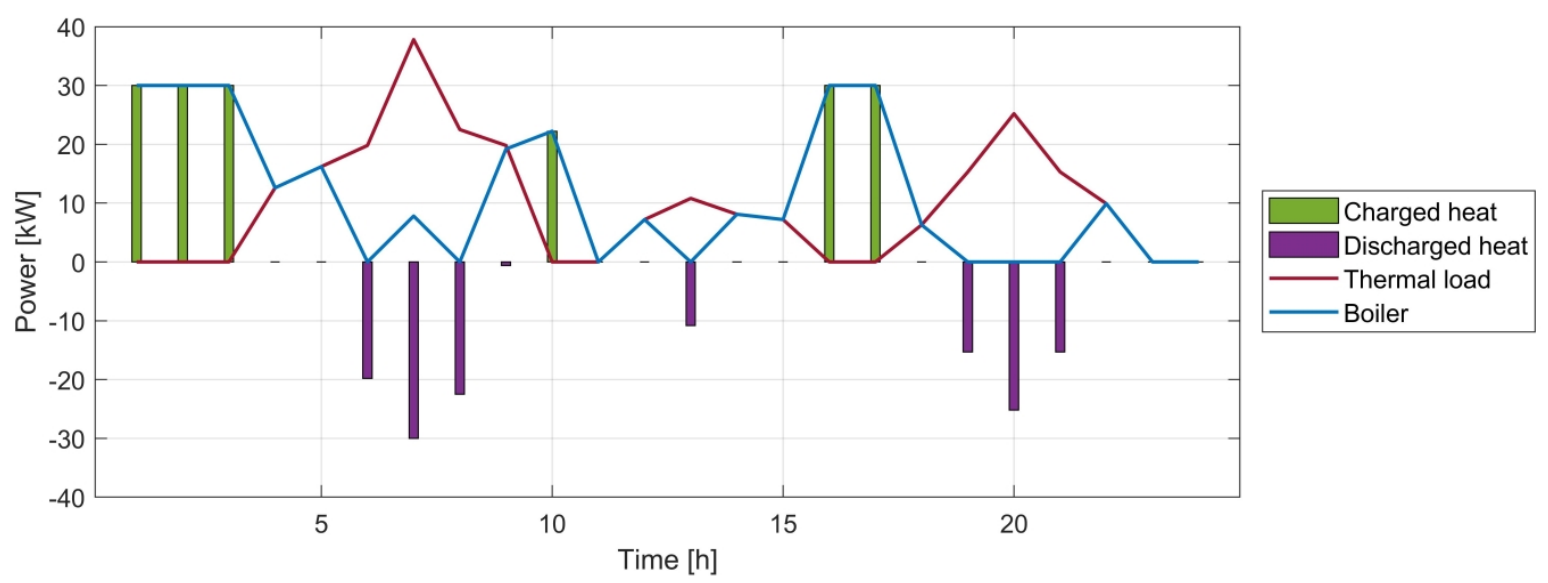

(c)

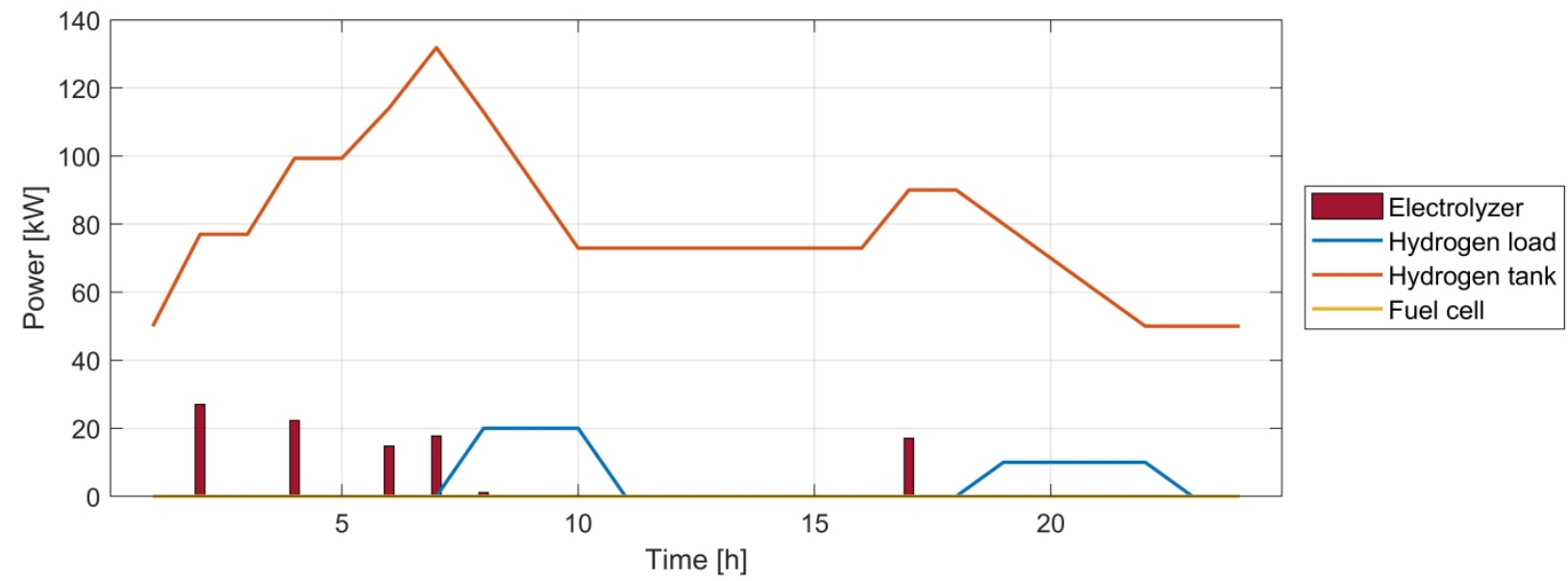

(d)

Fig. 7. Energy exchange under the risk-seeking strategy: (a) AC bus; (b) DC bus; (c) Heat; and (d) Hydrogen.

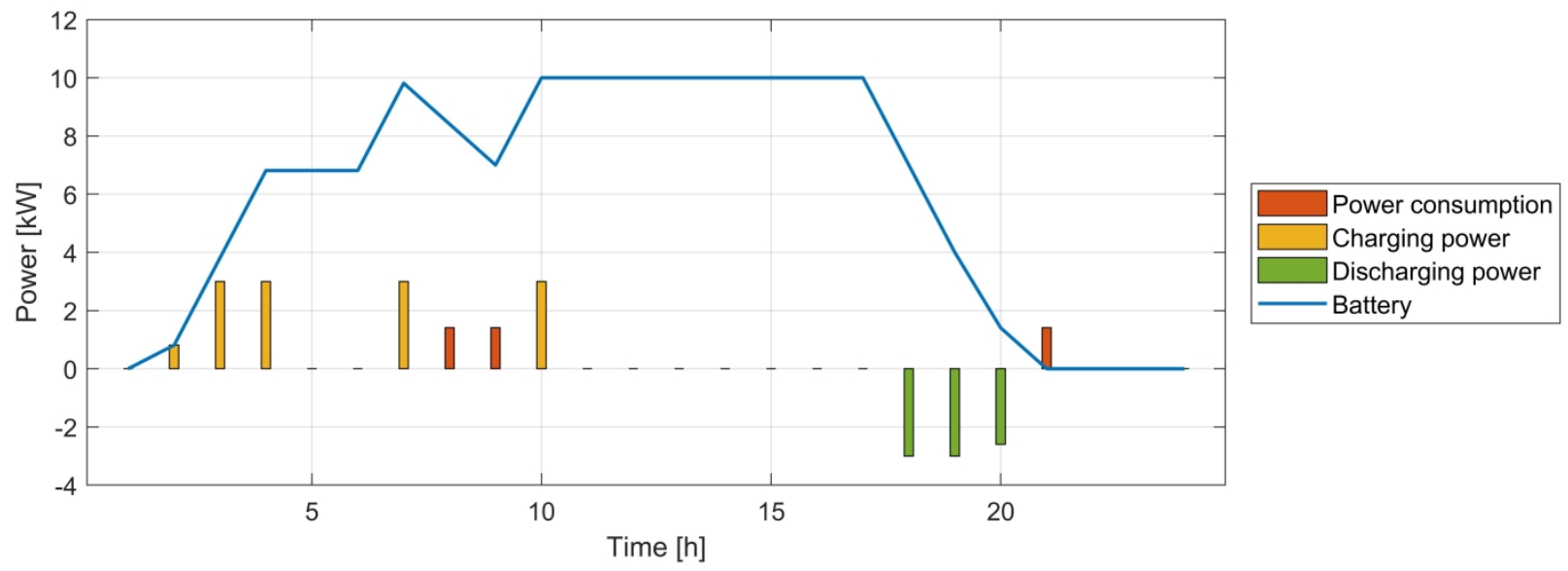

(a) 


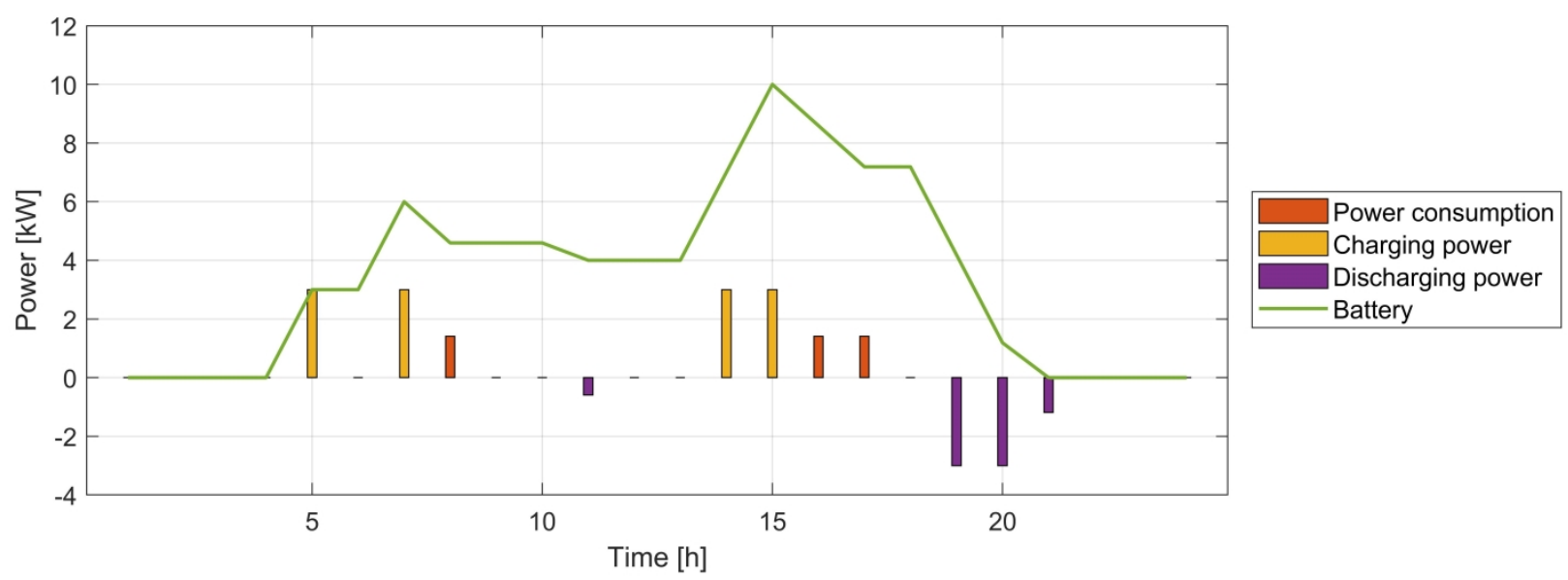

(b)

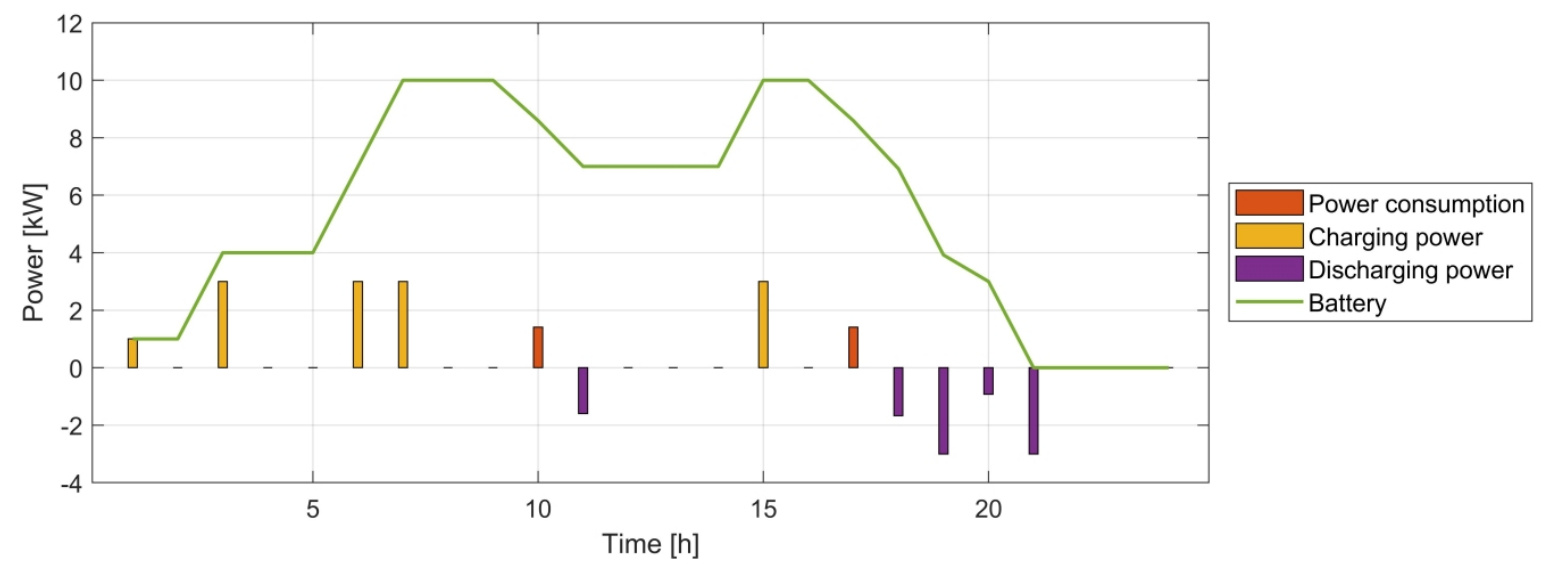

(c)

Fig. 8. Operating status of the considered PHEVs under the risk-seeking strategy: (a) PHEV 1; (b) PHEV 25; and (c) PHEV 50.

Under this strategy, as the power consumption of PHEVs decreases, purchased electricity from the power grid decreases and profits increase. For example, by setting the target profit at $\$ 20,131$ and solving the proposed opportunity objective function using GAMS, the minimum deviation from the predicted amount of power consumption would be equal to 26.1 percent and if the power consumption still decreases, the profit will be less than the target profit. Also, by decreasing the power consumption of PHEVs, the total discharging power of PHEVs increases and more power will be sold to the upstream power grid. As can be seen in Fig. 8, by decreasing the power consumption of the PHEV 1, a higher amount of its energy is discharged. This is also valid for the PHEVs 25 and 50.

\subsection{Sensitivity analyses}

In this sub-section, we report on two-way sensitivity analyses, carried out to assess the effects of changes in the number of employed PHEVs as well as the deviation factors under the risk-averse and risk-seeking strategies on the respective robustness and opportunity parameters. In this regard, we first varied the number of adopted PHEVs in the riskconstrained optimal energy management from 5 to 50 in intervals of 5 , whilst also varying the deviation factors from 0 to 0.8 for the risk-averse strategy and to 0.7 for the risk-seeking strategy. In this manner, we created 90 and 80 combinations of the number of integrated PHEVs and deviation factor respectively for the risk-averse and risk-seeking strategies. Finally, we applied the proposed risk-based model to each combination of the number of PHEVs and deviation factor. The undertaken sensitivity analyses are shown in Figs. 9 and 10. As can be seen in Fig. 9, increasing the number of integrated PHEVs into the system and/or the risk-averse deviation factor, increases the robustness parameter monotonically, but not linearly. In other words, the operator of a system with a greater number of employed 
PHEVs has a better ability to make robust decisions against the forecasted overall behavior of the fleet of PHEVs. Also, we note from Fig. 10 that the robustness parameter for every number of adopted PHEVs has a saturation point, past which a further increase in the risk-averse deviation factor would not alter it anymore. On the other hand, it is apparent from Fig. 10 that increasing the number of adopted PHEVs and/or risk-seeking deviation factor, increases the opportunity factor monotonically, though not proportionally. Put differently, the system operator will get a better opportunity to take advantage of the uncertainty in the predicted driving patterns of the PHEVs if the number of utilized vehicles increases. In our view, the results of the uncertainty analyses emphasize the robustness and validity of our proposed risk-driven approach to accommodate the uncertainty associated with power consumption of PHEVs, while optimally operating the energy system that incorporates them.

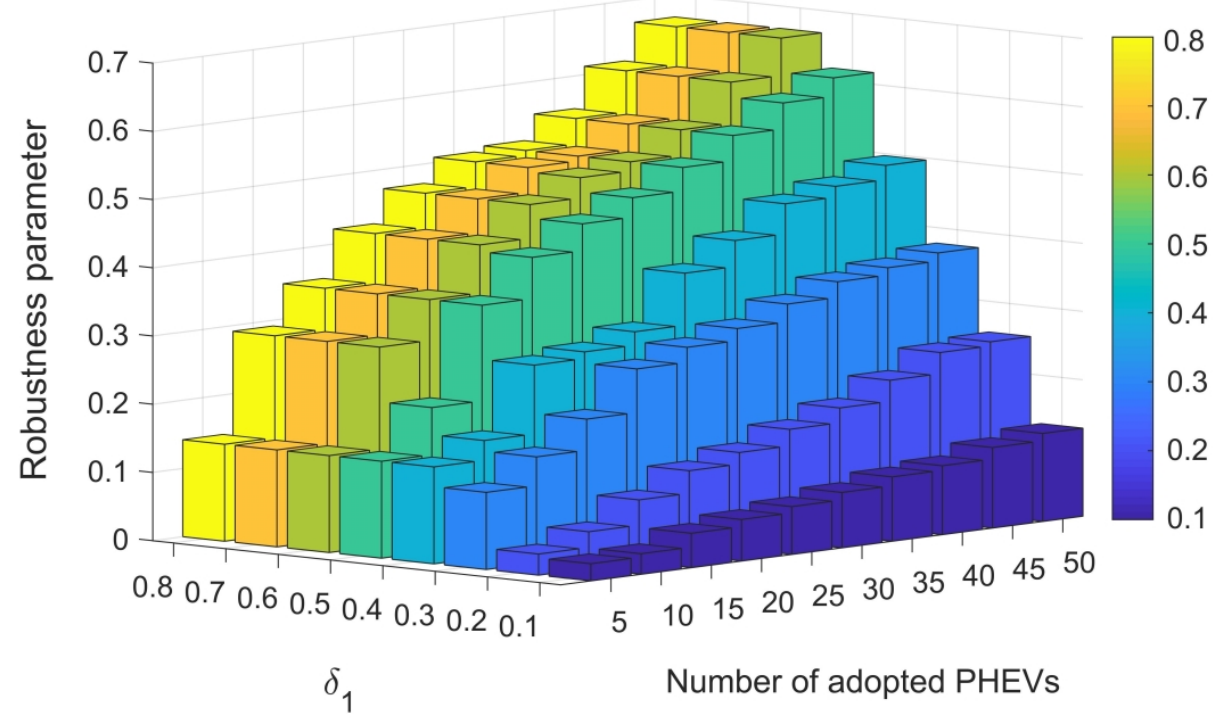

Fig. 9. Sensitivity of the robustness parameter to the risk-averse deviation factor and the number of PHEVs.

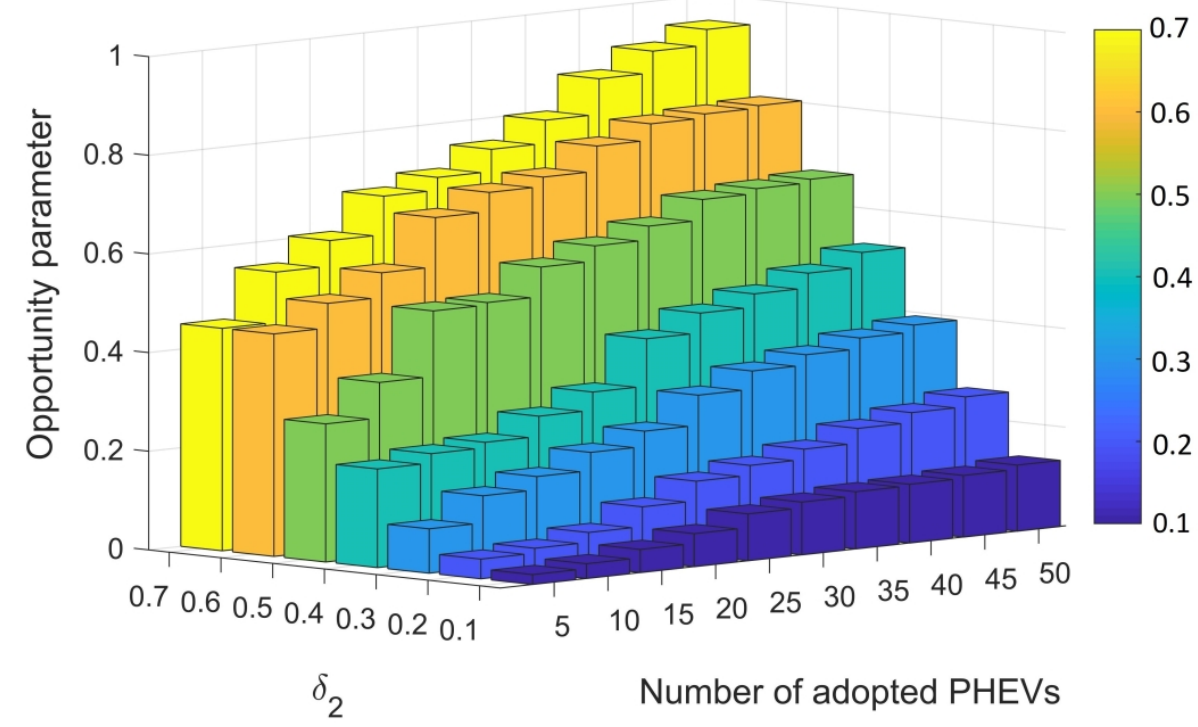

Fig. 10. Sensitivity of the opportunity parameter to the risk-seeking deviation factor and the number of PHEVs. 


\section{Conclusion and future work}

In this paper, risk-based optimal operation of an energy hub in the presence of uncertainty associated with the power consumption of PHEVs during trips is studied. The proposed energy hub has a bilateral power exchange with the upstream power grid and a unilateral power exchange with the upstream natural gas network and includes photovoltaic panels, wind turbines, PHEVs, FCVs, an inverter, a rectifier, a hydrogen subsystem, a boiler, and a heat storage system. The proposed model is solved using GAMS software under both risk-averse and risk-seeking strategies by applying the robustness and opportunity functions of IGDT, respectively. Based on solving the robustness function of IGDT for each deviation factor of profit under the risk-averse strategy, the tolerable amount of uncertainty for predicted power consumption is calculated to achieve a minimum amount of profit. On the other hand, based on solving the opportunity function of IGDT for each deviation of profit under the risk-seeking strategy, the minimum deviation from the predicted value of power consumption in order to achieve maximum profit is calculated. In fact, the results obtained from the robustness and opportunity functions help the energy hub operator to take appropriate decisions for coping with various levels of uncertainty associated with the power consumption of PHEVs during trips. In addition, the adaptive risk-constrained modeling framework developed in this paper is not principally targeted and limited to relatively small residential complexes. In fact, the proposed risk assessment model can be applied to other forms of renewable and sustainable energy systems - micro-grids, nano-grids, virtual power plants, load aggregators, and so forth - with lower or higher targeted populations. Future work will concentrate on developing a risk-based model for the optimal operation of energy hubs that considers the uncertainty associated with the power consumption of PHEVs together with the uncertainty associated with other variables of the system such as electrical and thermal loads, solar radiation, wind speed, and market prices. In this respect, research into solving this problem is already underway to develop a new improved version of the standard IGDT, which enables the simultaneous modeling of several uncertain parameters in order to tackle the uncertainty in simulation results more accurately, whilst also taking advantage of exact mathematical uncertainty modeling benefits of the original IGDT.

\section{References}

[1] S. Bahramara and H. Golpîra, "Robust optimization of micro-grids operation problem in the presence of electric vehicles,” Sustain. Cities Soc., vol. 37, pp. 388-395, 2018.

[2] J. Cook et al., "Quantifying the consensus on anthropogenic global warming in the scientific literature," Env. Res Lett, vol. 8, no. 2, 2013.

[3] W. R. L. Anderegg, J. W. Prall, J. Harold, and S. H. Schneider, "Expert credibility in climate change," Proc. Natl. Acad. Sci., vol. 107, no. 27, pp. 12107-12109, 2010.

[4] M. Contestabile, G. J. Offer, R. Slade, F. Jaeger, and M. Thoennes, "Battery electric vehicles, hydrogen fuel cells and biofuels. Which will be the winner?,” Energy Environ. Sci., vol. 4, no. 10, pp. 3754-3772, 2011.

[5] C. De Jonghe, E. Delarue, R. Belmans, and W. D'haeseleer, "Interactions between measures for the support of electricity from renewable energy sources and CO2mitigation," Energy Policy, vol. 37, no. 11, pp. 47434752, 2009.

[6] Y. Liu and C. Cirillo, "Modeling green vehicle adoption: An integrated approach for policy evaluation," Int. J. Sustain. Transp., vol. 12, no. 7, pp. 473-483, 2018.

[7] N. Phuangpornpitak and S. Tia, "Opportunities and challenges of integrating renewable energy in smart grid system," Energy Procedia, vol. 34, pp. 282-290, 2013.

[8] C. M. Martinez, X. Hu, D. Cao, E. Velenis, B. Gao, and M. Wellers, "Energy Management in Plug-in Hybrid Electric Vehicles: Recent Progress and a Connected Vehicles Perspective," IEEE Trans. Vehic. Technol., vol. 66, no. 6, pp. 4534-4549, 2017.

[9] T. Liu, X. Hu, S. E. Li, and D. Cao, "Reinforcement Learning Optimized Look-Ahead Energy Management of a Parallel Hybrid Electric Vehicle," IEEE/ASME Trans. Mechat., vol. 22, no. 4, pp. 1497-1507, 2017.

[10] S. M. Moghaddas-Tafreshi, S. Mohseni, M. E. Karami, and S. Kelly, "Optimal energy management of a 
grid-connected multiple energy carrier micro-grid," Appl. Therm. Eng., vol. 152, pp. 796-806, 2019.

[11] T. Haneda, Y. Ono, T. Ikegami, and A. Akisawa, "Technological assessment of residential fuel cells using hydrogen supply systems for fuel cell vehicles," Int. J. Hydrogen Energy, vol. 42, no. 42, pp. 26377-26388, 2017.

[12] Y. Hames, K. Kaya, E. Baltacioglu, and A. Turksoy, "Analysis of the control strategies for fuel saving in the hydrogen fuel cell vehicles,” Int. J. Hydrogen Energy, vol. 43, no. 23, pp. 10810-10821, 2018.

[13] M. Becherif, M. C. Péra, D. Hissel, and Z. Zheng, "Determination of the health state of fuel cell vehicle for a clean transportation," J. Clean. Prod., vol. 171, pp. 1510-1519, 2018.

[14] M. D. Galus and G. Andersson, "Integration of Plug-In Hybrid Electric Vehicles into energy networks," in Proceedings of the 2009 IEEE Bucharest PowerTech Innov. Ideas Towar. Electr. Grid Futur., Bucharest, Romania, 28 June-2 July 2009 pp. 1-8.

[15] R. C. Green, L. Wang, and M. Alam, "The impact of plug-in hybrid electric vehicles on distribution networks: A review and outlook," Renew. Sustain. Energy Rev., vol. 15, no. 1, pp. 544-553, 2011.

[16] L. Göransson, S. Karlsson, and F. Johnsson, "Integration of plug-in hybrid electric vehicles in a regional wind-thermal power system," Energy Policy, vol. 38, no. 10, pp. 5482-5492, 2010.

[17] S. Mohseni and S. M. Moghaddas-Tafreshi, "A multi-agent system for optimal sizing of a cooperative selfsustainable multi-carrier microgrid,” Sustain. Cities Soc., vol. 38, pp. 452-465, 2018.

[18] A. Dolatabadi and B. Mohammadi-Ivatloo, "Stochastic risk-constrained scheduling of smart energy hub in the presence of wind power and demand response," Appl. Therm. Eng., vol. 123, pp. 40-49, 2017.

[19] A. Parisio, C. Del Vecchio, and A. Vaccaro, "A robust optimization approach to energy hub management," Int. J. Electr. Power Energy Syst., vol. 42, no. 1, pp. 98-104, 2012.

[20] S. Nojavan, M. Majidi, and K. Zare, "Performance improvement of a battery/PV/fuel cell/grid hybrid energy system considering load uncertainty modeling using IGDT," Energy Convers. Manag., vol. 147, pp. 29-39, 2017.

[21] S. Nojavan, M. Majidi, and K. Zare, "Risk-based optimal performance of a PV/fuel cell/battery/grid hybrid energy system using information gap decision theory in the presence of demand response program," Int. J. Hydrogen Energy, vol. 42, no. 16, pp. 11857-11867, 2017.

[22] W. Su, J. Wang, K. Zhang, and A. Q. Huang, "Model predictive control-based power dispatch for distribution system considering plug-in electric vehicle uncertainty," Electr. Power Syst. Res., vol. 106, pp. 29-35, 2014.

[23] S. Xie, X. Hu, Z. Xin, and L. Li, "Time-Efficient Stochastic Model Predictive Energy Management for a Plug-In Hybrid Electric Bus With an Adaptive Reference State-of-Charge Advisory," IEEE Trans. Vehic. Technol., vol. 67, no. 7, pp. 5671-5682, 2018.

[24] Y. Ben-Haim, Info-Gap Decision Theory: Decisions Under Severe Uncertainty, 2nd ed. San Diego: Academic Press, 2006.

[25] B. Mohammadi-Ivatloo, H. Zareipour, N. Amjady, and M. Ehsan, "Application of information-gap decision theory to risk-constrained self-scheduling of GenCos," IEEE Trans. Power Syst., vol. 28, no. 2, pp. 10931102, 2013.

[26] M. Aien, A. Hajebrahimi, and M. Fotuhi-Firuzabad, "A comprehensive review on uncertainty modeling techniques in power system studies,” Renew. Sustain. Energy Rev., vol. 57, pp. 1077-1089, 2016.

[27] J. P. Fossati, A. Galarza, A. Martín-Villate, J. M. Echeverría, and L. Fontán, "Optimal scheduling of a microgrid with a fuzzy logic controlled storage system," Int. J. Electr. Power Energy Syst., vol. 68, pp. 6170, 2015.

[28] I. Prodan and E. Zio, "A model predictive control framework for reliable microgrid energy management," Int. J. Electr. Power Energy Syst., vol. 61, pp. 399-409, 2014.

[29] C. Sun, F. Sun, and S. J. Moura, "Nonlinear predictive energy management of residential buildings with 
photovoltaics \& batteries," J. Power Sources, vol. 325, pp. 723-731, 2016.

[30] M. J. Vahid-Pakdel, S. Nojavan, B. Mohammadi-ivatloo, and K. Zare, "Stochastic optimization of energy hub operation with consideration of thermal energy market and demand response," Energy Convers. Manag., vol. 145, pp. 117-128, 2017.

[31] A. R. Hota, M. Juvvanapudi, and P. Bajpai, "Issues and solution approaches in PHEV integration to the smart grid,” Renew. Sustain. Energy Rev., vol. 30, pp. 217-229, 2014.

[32] T. Sattarpour, D. Nazarpour, and S. Golshannavaz, "A multi-objective HEM strategy for smart home energy scheduling: A collaborative approach to support microgrid operation," Sustain. Cities Soc., vol. 37, pp. 2633, 2018.

[33] H. Kamankesh, V. G. Agelidis, and A. Kavousi-Fard, "Optimal scheduling of renewable micro-grids considering plug-in hybrid electric vehicle charging demand," Energy, vol. 100, pp. 285-297, 2016.

[34] X. Wu, X. Hu, Y. Teng, S. Qian, and R. Cheng, "Optimal integration of a hybrid solar-battery power source into smart home nanogrid with plug-in electric vehicle," J. Power Sources, vol. 363, pp. 277-283, 2017.

[35] X. Wu, X. Hu, X. Yin, and S. J. Moura, "Stochastic Optimal Energy Management of Smart Home With PEV Energy Storage," IEEE Trans. Smart Grid, vol. 9, no. 3, pp. 2065-2075, 2018.

[36] D. Thomas, O. Deblecker, and C. S. Ioakimidis, "Optimal operation of an energy management system for a grid-connected smart building considering photovoltaics' uncertainty and stochastic electric vehicles' driving schedule," Appl. Energy, vol. 210, pp. 1188-1206, 2018.

[37] P. Aliasghari, B. Mohammadi-Ivatloo, M. Alipour, M. Abapour, and K. Zare, "Optimal scheduling of plug-in electric vehicles and renewable micro-grid in energy and reserve markets considering demand response program," J. Clean. Prod., vol. 186, pp. 293-303, 2018.'

[38] S. M. Moghaddas-Tafreshi, H. Ranjbarzadeh, M. Jafari, and H. Khayyam, “A probabilistic unit commitment model for optimal operation of plug-in electric vehicles in microgrid," Renew. Sustain. Energy Rev., vol. 66, pp. 934-947, 2016.

[39] A. Najafi-Ghalelou, S. Nojavan, and K. Zare, "Heating and power hub models for robust performance of smart building using information gap decision theory," Int. J. Electr. Power Energy Syst., vol. 98, pp. 23$35,2018$.

[40] A. Mehdizadeh, N. Taghizadegan, and J. Salehi, "Risk-based energy management of renewable-based microgrid using information gap decision theory in the presence of peak load management," Appl. Energy, vol. 211, pp. 617-630, 2018.

[41] A. Soroudi, A. Rabiee, and A. Keane, "Information gap decision theory approach to deal with wind power uncertainty in unit commitment," Electr. Power Syst. Res., vol. 145, pp. 137-148, 2017.

[42] A. Najafi-Ghalelou, S. Nojavan, and K. Zare, "Information gap decision theory-based risk-constrained scheduling of smart home energy consumption in the presence of solar thermal storage system," Sol. Energy, vol. 163, pp. 271-287, 2018.

[43] M. S. Javadi, A. Anvari-Moghaddam, and J. M. Guerrero, "Robust energy hub management using information gap decision theory," in Proceedings of the IECON 2017 - 43rd Annu. Conf. IEEE Ind. Electron. Soc., Beijing, China, 29 Oct.-1 Nov. 2017, pp. 410-415.

[44] A. Dolatabadi, M. Jadidbonab, and B. Mohammadi-ivatloo, "Short-term Scheduling Strategy for WindBased Energy Hub: A Hybrid Stochastic/IGDT Approach," IEEE Trans. Sustain. Energy, vol. 10, no. 1, pp. 438-448, 2018.

[45] L. Xia, I. Mareels, T. Alpcan, M. Brazil, J. de Hoog, and D. A. Thomas, "A distributed electric vehicle charging management algorithm using only local measurements," in Proceedings of the 2014 IEEE PES Innov. Smart Grid Technol. Conf. (ISGT), Washington, DC, USA, 19-22 Feb. 2014, pp. 1-5.

[46] X. Hu, D. Cao, and B. Egardt, "Condition Monitoring in Advanced Battery Management Systems: Moving Horizon Estimation Using a Reduced Electrochemical Model," IEEE/ASME Trans. Mechat., vol. 23, no. 1, pp. 167-178, 2018. 
[47] E. Mashhur and S. M. Moghaddas-Tafreshi, "Mathematical modeling of electrochemical storage for incorporation in methods to optimize the operational planning of an interconnected micro grid," J. Zhejiang University SCI. C., vol. 11, no. 9, pp. 737-750, 2010.

[48] S. Mohseni and S. M. Moghaddas-Tafreshi, "Development of a Multi-Agent System for Optimal Sizing of a Commercial Complex Microgrid," in Proceedings of the $5^{\text {th }}$ Iranian Conference on Renewable Energy \& Distributed Generation (ICREDG2017), Rasht, Iran, 8-9 Mar. 2017, pp. 1-6.

[49] S. M. Moghaddas-Tafreshi and S. M. Hakimi, "Optimal sizing of a stand-alone hybrid power system via particle swarm optimization (PSO)," in Proceedings of the 2007 International Power Engineering Conference (IPEC 2007), Singapore, Singapore, 3-6 Dec. 2007, pp. 1-6.

[50] A. Hajimiragha, C. Canizares, M. Fowler, M. Geidl, and G. Andersson, "Optimal Energy Flow of integrated energy systems with hydrogen economy considerations," in Proceedings of the 2007 iREP Symp. - Bulk Power Syst. Dyn. Control - VII. Revital. Oper. Reliab., Charleston, SC, USA, 19-24 Aug. 2007, pp. 1-11.

[51] Z. Hashemi, A. Ramezani, and M. Parsa Moghaddam, "Energy hub management by using decentralized robust model predictive control," in Proceedings of the 4th International Conference on Control, Instrumentation, and Automation (ICCIA), Qazvin, Iran, 27-28 Jan. 2016, pp. 105-110.

[52] G. Cau, D. Cocco, M. Petrollese, S. Knudsen Kær, and C. Milan, "Energy management strategy based on short-term generation scheduling for a renewable microgrid using a hydrogen storage system," Energy Convers. Manag., vol. 87, pp. 820-831, 2014.

[53] S. Mohseni and S. M. Moghaddas-Tafreshi, "A Multi-Agent Approach to Optimal Sizing of a Combined Heating and Power Microgrid," in Proceedings of the $5^{\text {th }}$ Iranian Conference on Renewable Energy \& Distributed Generation (ICREDG2017), Rasht, Iran, 8-9 Mar. 2017, pp. 1-6.

[54] T. Kanungo et al., "An efficient k-means clustering algorithm: Analysis and implementation," IEEE Trans. Patt. Anal. Mach. Intell., vol. 24, pp. 881-892, 2002.

[55] Anonymous, "Compare Electric Cars and Plug-in Hybrids By Features, Price, Range," 2019. [Online]. Available: https://www.plugincars.com/cars. [Accessed: 03-Apr.-2019]. 


\title{
Optimal operation of an energy hub considering the uncertainty associated with the power consumption of plug-in hybrid electric vehicles using information gap decision theory
}

\author{
Seyed Masoud Moghaddas-Tafreshia, ${ }^{a,}$, Morteza Jafari ${ }^{a}$, Soheil Mohseni ${ }^{a, b}$, Scott Kelly ${ }^{c}$ \\ ${ }^{a}$ Department of Electrical Engineering, Faculty of Engineering, University of Guilan, Rasht, Iran \\ ${ }^{b}$ Chair in Sustainable Energy Systems, School of Engineering and Computer Science, Faculty of Engineering, Victoria \\ University of Wellington, Wellington 6140, New Zealand \\ ${ }^{c}$ Institute for Sustainable Futures, University of Technology Sydney, NSW, Australia \\ * Corresponding author, Email: tafreshi@guilan.ac.ir
}

Additional file 1

Table S1. Temporal behaviors (driving patterns) of the considered fleet 50 PHEVs.

\begin{tabular}{|c|c|c|c|c|c|}
\hline PHEV number & $t_{l h[\mathrm{~h}]}$ & $t_{a w[\mathrm{~h}]}$ & $t_{l w[\mathrm{~h}]}$ & $t_{a h[\mathrm{~h}]}$ & $V_{V}[\mathrm{~km} / \mathrm{h}]$ \\
\hline 1 & 7 & 9 & 20 & 21 & 30 \\
\hline 2 & 8 & 10 & 20 & 21 & 31 \\
\hline 3 & 8 & 9 & 14 & 16 & 26 \\
\hline 4 & 6 & 7 & 17 & 19 & 34 \\
\hline 5 & 7 & 8 & 19 & 20 & 37 \\
\hline 6 & 7 & 8 & 17 & 18 & 20 \\
\hline 7 & 8 & 10 & 19 & 20 & 38 \\
\hline 8 & 7 & 8 & 17 & 19 & 29 \\
\hline 9 & 8 & 9 & 15 & 16 & 27 \\
\hline 10 & 8 & 10 & 16 & 17 & 35 \\
\hline 11 & 7 & 8 & 18 & 19 & 34 \\
\hline 12 & 8 & 9 & 20 & 21 & 28 \\
\hline 13 & 7 & 8 & 14 & 16 & 24 \\
\hline 14 & 7 & 8 & 15 & 17 & 21 \\
\hline 15 & 9 & 10 & 16 & 17 & 22 \\
\hline 16 & 7 & 8 & 18 & 19 & 36 \\
\hline 17 & 6 & 7 & 16 & 17 & 30 \\
\hline 18 & 6 & 7 & 15 & 16 & 33 \\
\hline 19 & 8 & 9 & 15 & 16 & 22 \\
\hline 20 & 9 & 10 & 18 & 19 & 28 \\
\hline 21 & 5 & 7 & 15 & 16 & 34 \\
\hline 22 & 8 & 10 & 20 & 21 & 30 \\
\hline 23 & 9 & 10 & 19 & 20 & 23 \\
\hline 24 & 7 & 8 & 16 & 17 & 28 \\
\hline 25 & 7 & 8 & 15 & 17 & 35 \\
\hline 26 & 8 & 9 & 18 & 20 & 32 \\
\hline 27 & 7 & 9 & 19 & 20 & 26 \\
\hline 28 & 7 & 8 & 17 & 19 & 37 \\
\hline 29 & 8 & 9 & 17 & 18 & 24 \\
\hline 30 & 9 & 10 & 16 & 18 & 29 \\
\hline 31 & 10 & 11 & 20 & 21 & 38 \\
\hline 32 & 7 & 8 & 15 & 17 & 25 \\
\hline 33 & 7 & 8 & 16 & 18 & 34 \\
\hline 34 & 7 & 9 & 18 & 19 & 37 \\
\hline 35 & 7 & 9 & 15 & 16 & 31 \\
\hline 36 & 7 & 9 & 19 & 20 & 29 \\
\hline 37 & 7 & 8 & 15 & 16 & 22 \\
\hline 38 & 6 & 7 & 16 & 17 & 33 \\
\hline 39 & 9 & 10 & 18 & 20 & 28 \\
\hline 40 & 8 & 10 & 18 & 19 & 36 \\
\hline 41 & 9 & 10 & 16 & 17 & 30 \\
\hline 42 & 7 & 8 & 20 & 21 & 25 \\
\hline 43 & 8 & 10 & 19 & 21 & 38 \\
\hline 44 & 9 & 10 & 18 & 20 & 26 \\
\hline 45 & 8 & 9 & 15 & 16 & 24 \\
\hline 46 & 6 & 8 & 16 & 17 & 31 \\
\hline 47 & 10 & 11 & 14 & 15 & 35 \\
\hline 48 & 8 & 9 & 18 & 19 & 28 \\
\hline 49 & 8 & 9 & 16 & 18 & 37 \\
\hline 50 & 9 & 10 & 16 & 17 & 25 \\
\hline
\end{tabular}

